Board of Governors of the Federal Reserve System

International Finance Discussion Papers

Number 857

April 2006

Modeling Direct Investment Valuation Adjustments and Estimating Quarterly Positions

Jane Ihrig

and

Jaime Marquez

NOTE: International Finance Discussion Papers are preliminary materials circulated to stimulate discussion and critical comment. References in publications to International Finance Discussion Papers (other than an acknowledgment that the writer has had access to unpublished material) should be cleared with the author or authors. Recent IFDPs are available on the Web at www.federalreserve.gov/pubs/ifdp/. 


\title{
Modeling Direct Investment Valuation Adjustments and Estimating Quarterly Positions
}

\author{
Jane Ihrig* \\ and \\ Jaime Marquez
}

\begin{abstract}
This paper takes an in-depth look at U.S. direct investment valuation adjustments. We develop a methodology to generate valuation adjustments at the quarterly frequency, which can be combined with the Bureau of Economic Analysis's quarterly direct investment flows to obtain quarterly estimates of direct investment assets and liabilities. Our methodology involves two steps. First, we estimate valuation adjustment models with annual data. Our models rely on variables that reflect terms used by the Bureau of Economic Analysis in their data construction: exchange-rate changes, changes in the price of products, and changes in stock-market prices. Second, we apply quarterly data to the estimated models to generate quarter valuations and implement a procedure that ensures that the estimated valuations for the four quarters in a given year sum to the reported annual valuation adjustments. With this framework we consider how asset price shocks affect the net direct investment position and, hence, net international investment position.
\end{abstract}

JEL classification: C51, C53, F21, F37, F47

Keywords: net direct investment position, net international investment position, exchange rates, stock markets.

* A previous version of this paper was presented in the workshop series of the Federal Reserve Board. We thank Dale Henderson and Charlie Thomas for many helpful discussions, and Jillian Faucette and Stephen Gardner for research assistance. The calculations use Portable Troll version 1.7 from Intex Solutions and PcGive (see Hendry and Doornik (1999)). The views in this paper are solely the responsibility of the authors and should not be interpreted as reflecting the views of the Board of Governors of the Federal Reserve System or of any other person associated with the Federal Reserve System. This paper can be downloaded without charge from Social Science Research Network electronic library at http://www.ssrn.com/ . 


\section{Introduction}

This paper takes an in-depth look at direct investment valuation adjustments. First, we estimate models of valuation adjustments for both the direct investment position in the United States and U.S. position abroad, both measured at current cost and market value. Then we use these models to provide quarterly valuation adjustments and positions, something that is not provided by the Bureau of Economic Analysis (BEA). Finally, we use the models to illustrate how valuation adjustments respond to asset price shocks.

The fact that valuation adjustments matter is clear from figure 1, which shows the net direct investment position of the United States under alternative valuation schemes. If one simply cumulates net direct investment flows from 1982 to 2004, then the United States has net claims on foreigners of approximately $\$ 250$ billion. Alternatively, if one adjusts the values of assets and liabilities for inflation and changes in exchange rates -what is known as current cost- then U.S. net claims on foreigners in 2004 is near $\$ 600$ billion. The $\$ 350$ billion difference between these two measures of the net direct investment position reflects valuation adjustments over these two decades. Another way to see the impact of valuation adjustments is to look at the net position valued at market value. Here we see the United States moved from being a net debtor of $\$ 250$ billion in 2001 to a net credit of $\$ 500$ billion in 2004, most of the change in the position reflects valuation adjustments associated with the decline in the U.S. stock market.

Interest in both the magnitude and volatility of these positions is not new. For example, Cline (2005), Lane and Milesi-Ferretti (2005), Higgins et al. (2005) and Gourinchas and Rey (2005a and 2005b) have focused on the role valuation adjustments play in the process of external adjustment of the United States. What is new in this paper is the development of a methodology to alleviate a key limitation of all previous work: reliance on annual data. Having valuation adjustments at the quarterly frequency is important for a variety of reasons. First, if one is interested in external adjustment, quarterly changes are quite informative and this model can help in analyzing this issue. Second, BEA yearend international investment position data (valuation adjustments and, hence, the position) are released with nearly a six month lag. Researchers who need an estimate of the international investment position can use our valuation adjustment models to generate estimates of the positions many months prior to the data release. Last, one can combine our estimated quarterly valuation adjustments with BEA's quarterly data for direct investment (DI) flows to obtain quarterly estimates of assets and liabilities. As far as we know, such data are not available until now. These quarterly models can be embedded in a detailed economy-wide model of the U.S. economy, such as that used by the Federal Reserve Board, for standard forecasting purposes.

The implementation of the method we provide is straightforward and it is consistent with the data published by the BEA. Greatly simplified, our methodology involves two steps. First, we estimate valuation adjustment models with annual data. Our models rely on variables that reflect terms used by BEA in their construction; that is, independent variables in the models include exchange-rate changes, changes in the price of products, and changes in stock-market prices. This construct allows us to determine the importance of any of these asset price changes on valuation adjustments, and hence, on the net direct investment position (NDIP). This feature not only allows us to better understand the driving factors behind the historic evolution of these series, but also allows us to form expectations of future movement in these valuation adjustments. Second, we combine quarterly data and the estimated models to generate quarter valuations, with the underlying constraint that the valuations for the four quarters in a given year sum to the annual valuation adjustments reported by BEA.

We begin our analysis in section 2 with an overview of valuation adjustments. The econometric models explaining these adjustments are presented in Section 3. Section 4 constructs the quarterly valuation adjust- 
Figure 1

\section{U.S. Net Direct Investment Position (NDIP) and Cumulated Flows}

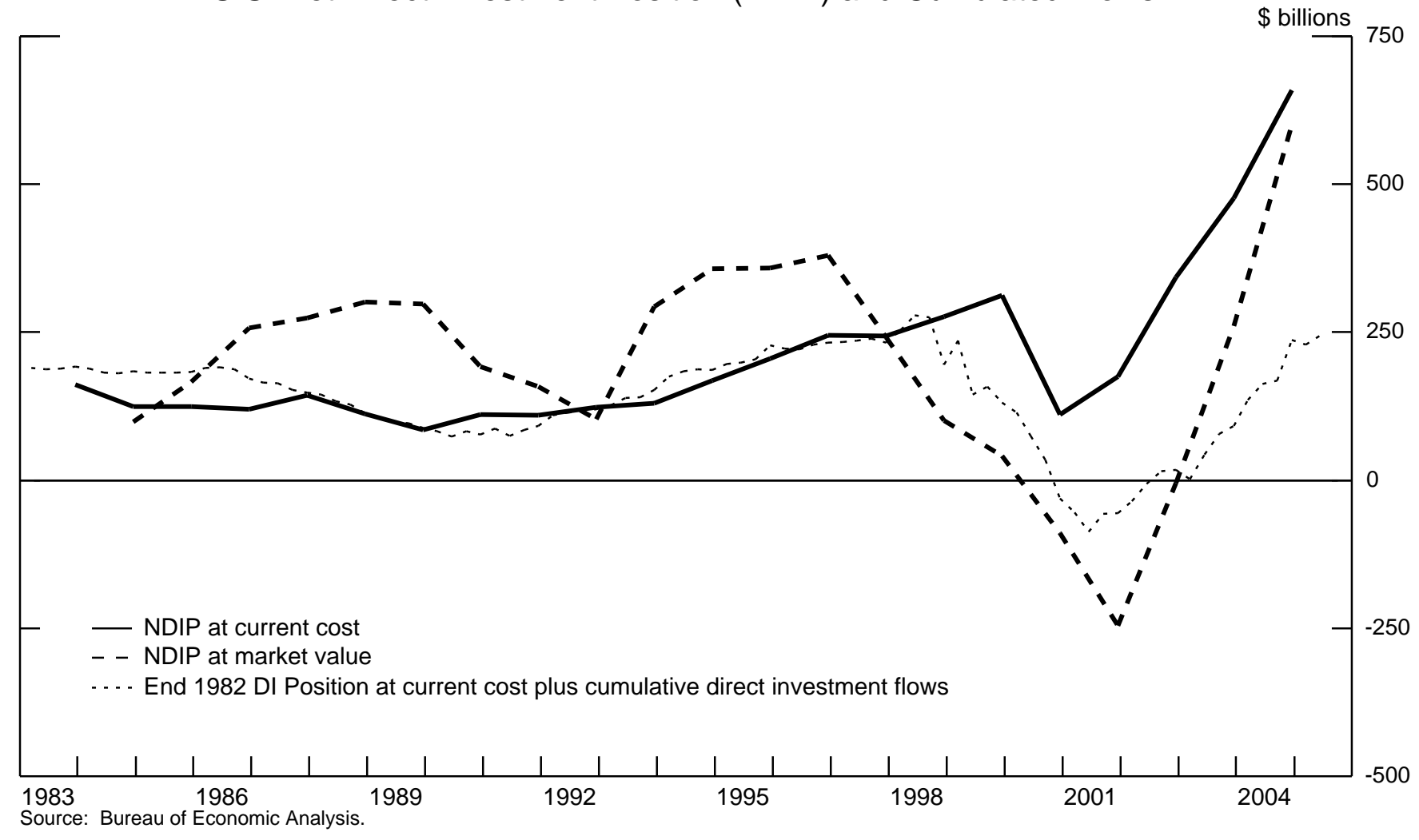


ments and quarterly positions that are consistent with BEA's annual data. Section 5 highlights how asset price shocks will affect the net direct investment position. Not only do we provide rules of thumb for how asset price shocks immediately affect the valuations but, we provide dynamic simulations to illustrate the longer-term effects on the valuation adjustments, DI positions and NDIP.

\section{Overview of Valuation Adjustments}

The BEA offers annual data for three measures of the U.S. DI position abroad and three measures of the DI position in the United States. These measures differ in the manner in how the stocks are valued: historical cost, current cost, and market value. The historical cost measure of direct investment values the DI position at book value, while current cost considers the value based on the current cost of plant and equipment, land, and inventories; the market-value measure insures the equity portion of the position is valued at current stock market prices.

Focusing on the current cost and market value measures, the change in the direct investment positions from one year to the next are a result of both flows and valuation adjustments. BEA decomposes the total valuation adjustments into three sources: exchange-rate adjustments, price adjustments, and "other." ${ }^{1}$ The exchange rate adjustment measures the effect of translating the previous year's dollar value of assets into the current year-end dollar value of assets. Since firms hedge and not all assets are in foreign currency, BEA's exchange rate adjustment for DI abroad is not directly proportional to the change in the value of the dollar over the year. ${ }^{2}$ The price adjustment varies by the type of valuation method one is using. For current cost, the price adjustment is for revaluing tangible assets using a perpetual inventory model for plant and equipment, general price indexes for land, and special adjustment factors for inventories. For positions valued at market value, the price adjustment reflects changes in the equity portion of the position associated with changes in stock market prices (i.e., revaluations associated with the local stock market). ${ }^{3}$ The third valuation adjustment term, denoted as "other" by BEA, seeks to capture changes in the value of holdings that are not captured by either DI flows, price changes in the stock, or foreign exchange-rate markets. Examples of other valuation adjustments include correction of errors in recording positions or flows; expropriation of assets by foreign governments; impairments of assets due to natural disasters; changes in the firm's good will and changes in coverage.

As shown in Figure 2, movements in the total valuation adjustment for the current-cost position abroad are volatile. For example, from 2000 to 2003 , the valuation adjustment swung from - $\$ 36$ billion to $\$ 56$ billion, an increase of $\$ 112$ billion. These swings are dominated by movements in exchange rates, which account for 46 percent of the volatility, and to a lesser extent by movements in foreign prices, which account for 21 percent of the volatility. Interestingly, movements in other valuation adjustments are not trivial and account for 33 percent of the volatility. Valuation effects due to prices and exchange rates are often of the opposite sign and thus tend to offset each other. When the valuation effects have the same sign, their combined effect can be substantial, as seen in 2003 and 2004 .

\footnotetext{
${ }^{1}$ See Landefeld and Lawson (1991) for more details.

${ }^{2}$ We find, over history, that the exchange rate valutaion adjustment on DI abroad at current cost is approximately 50 percent of the expected change in the position based on the change in the value of the dollar.

${ }^{3}$ Note that if the firm's equity is not traded in the foreign stock market, then market valuation will not pick up changes in good will. An example of a change in coverage is when a U.S. firm's acquisition of additional stock in a foreign firm results in the U.S. firm holding more than $10 \%$ of the stock of the foreign firm. In this case, the additional acquisition is recorded as direct investment flow; the U.S. firm's pre- $10 \%$ equity holdings are then recorded into Other Valuation Adjustments so that the DI position measures the full value of holdings of equity of the foreign firm. Note that these adjustments will also apply in instances when the U.S. firm's equity holdings fall below 10 percent.
} 


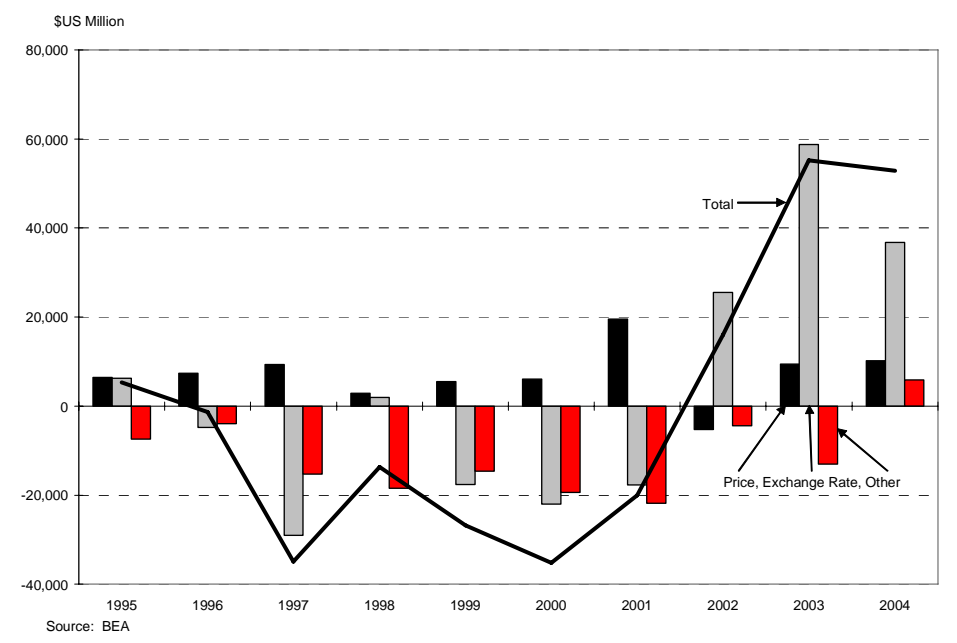

Figure 2 - Valuation Adjustments for DI abroad at current cost.

Figure 3 shows that the valuation adjustments for DI abroad at market value are even larger and more volatile than those for current cost (note the difference in scale of the y axis). In 2001, for example, the valuation adjustment was $-\$ 512$ billion, which is close to the U.S. current-account deficit for that year. From 2001 to 2004 , the valuation adjustment swung from $-\$ 512$ billion to $\$ 515$ billion, an increase of $\$ 1.2$ trillion. These swings are dominated by movements in stock prices, which account for 77 percent of the volatility. To a lesser extent movements in exchange rates influence this valuation adjustment, which account for 20 percent of the volatility; other valuation adjustments are, in general, small.

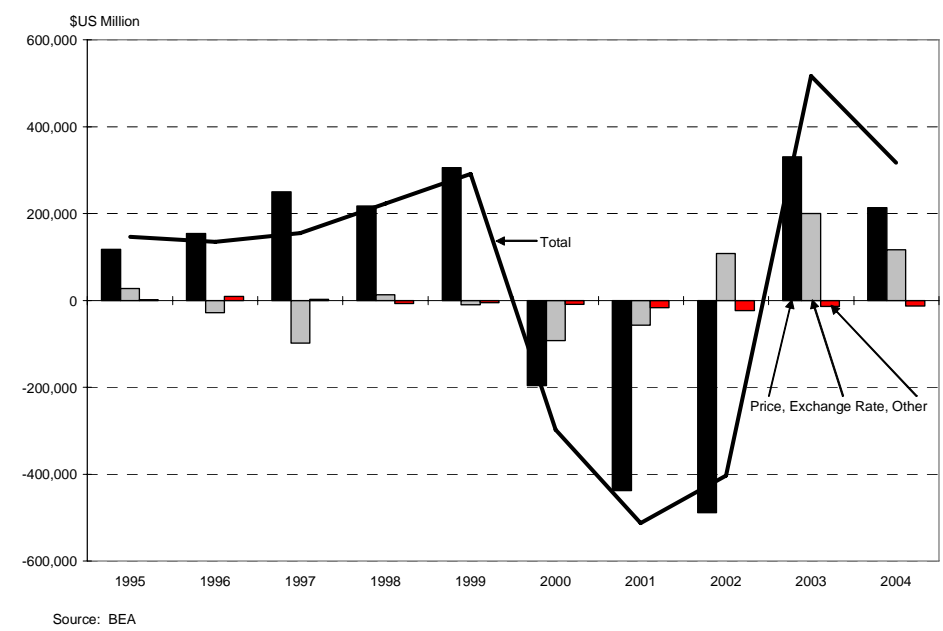

Figure 3 - Valuation adjustments for DI abroad at market value.

Figure 4 shows that, since 1995, movements in the valuation adjustments for DI in the United States have been dominated by factors other than prices and exchange rates: More than two-thirds of the volatility of the valuation adjustments stems from movements in other adjustments. Movements in U.S. prices account for one-quarter of the volatility of the valuation adjustment and, not surprisingly, exchange rate adjustments 
are a small portion of the adjustment, as we are focusing on dollar denominated DI in the United States.

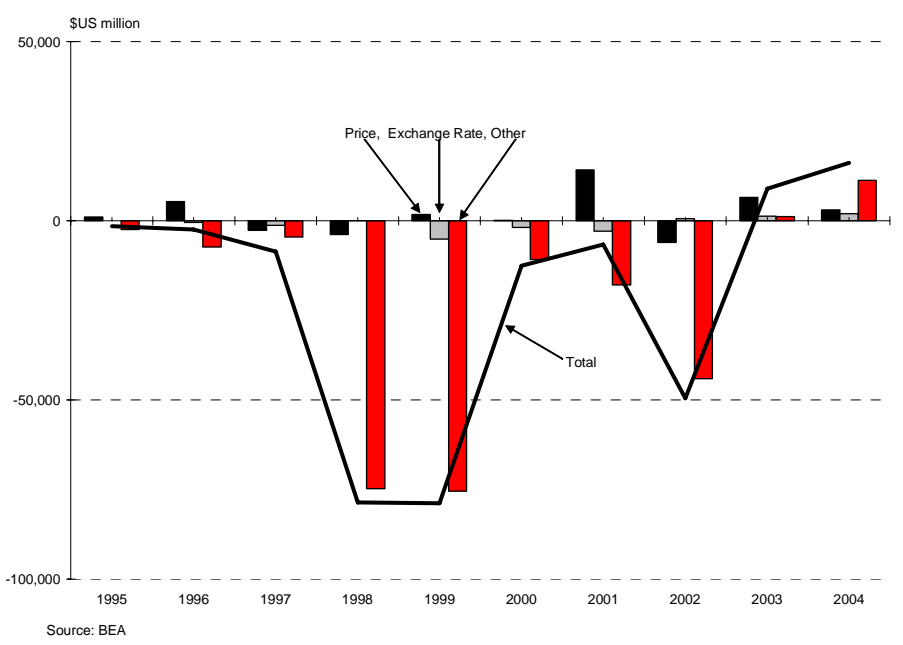

Figure 4 - Valuation adjustments for DI in the United States at current cost.

As in the case of DI abroad, market value adjustments for DI in the United States are large and volatile. As shown in Figure 5, the valuation adjustment was $-\$ 585$ billion in 2002, exceeding the U.S. current-account deficit for that year by $\$ 100$ billion. From 2002 to 2003, the valuation adjustment swung from $-\$ 585$ billion to $\$ 370$ billion, an increase of $\$ 960$ billion. These swings are dominated by movements in stock prices, which account for 97 percent of the volatility, and to a much lesser extent by movements in other valuation adjustments; valuation adjustments due to exchange rates are negligible.

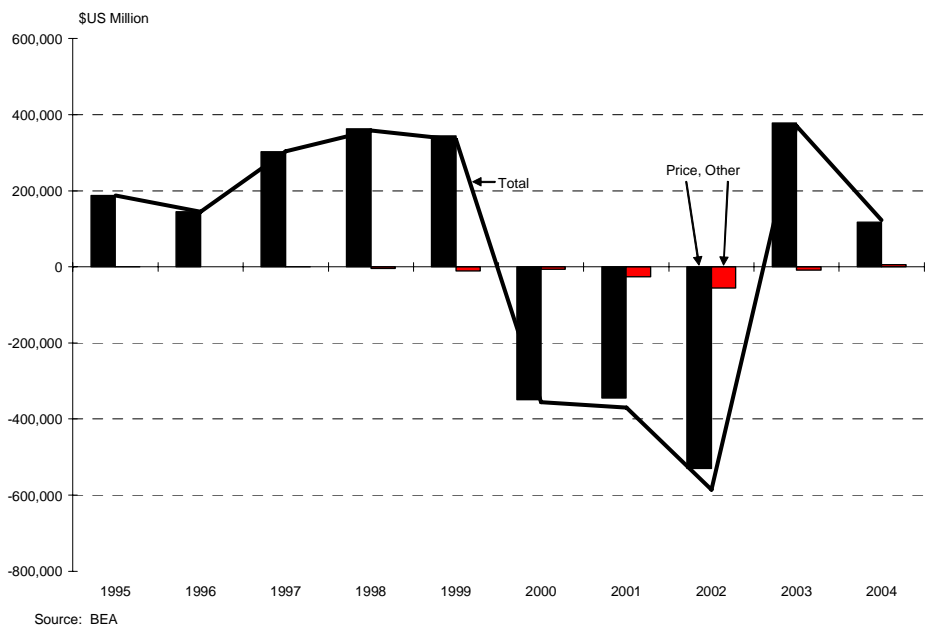

Figure 5 - Valuation adjustments for DI in the United States at market value.

Another way to emphasize the importance of the magnitude and volatility of these valuation adjustments is to compare the annual valuation adjustment in a given year to the DI flow in that year. Figures 6 and 7 illustrate that, on average, over the past decade the current cost valuation adjustments for DI Abroad and 
DI in the United States represent 20 percent and 30 percent of the annual DI flows, respectively. In 2002 the absolute value of the current cost valuation adjustment for DI in the United States was larger than the inflow.

The market value valuation adjustments tend to be much larger than those associated with current cost (figures 8 and 9). Here we see that, on average, valuation adjustments are over 200 percent of the flows. In 2002 the market value valuation adjustment was over 750 percent of the DI inflow into the United States!

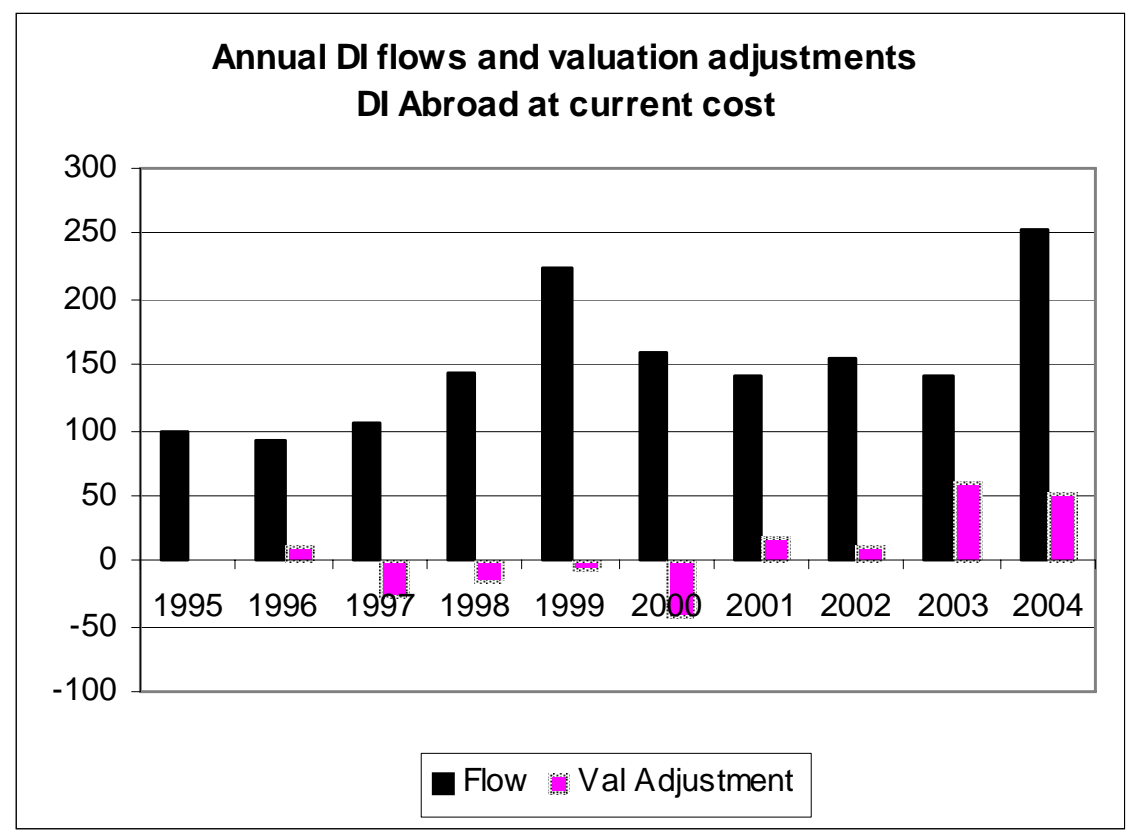

Figure 6

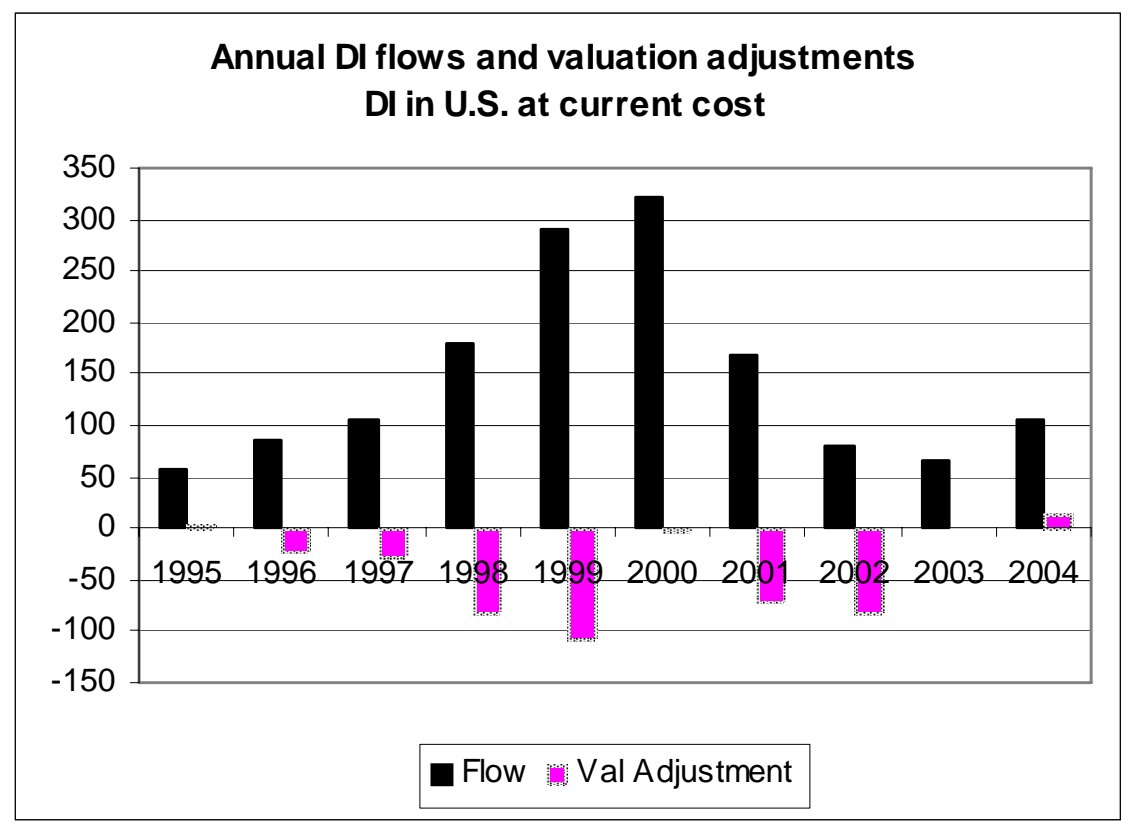

Figure 7 


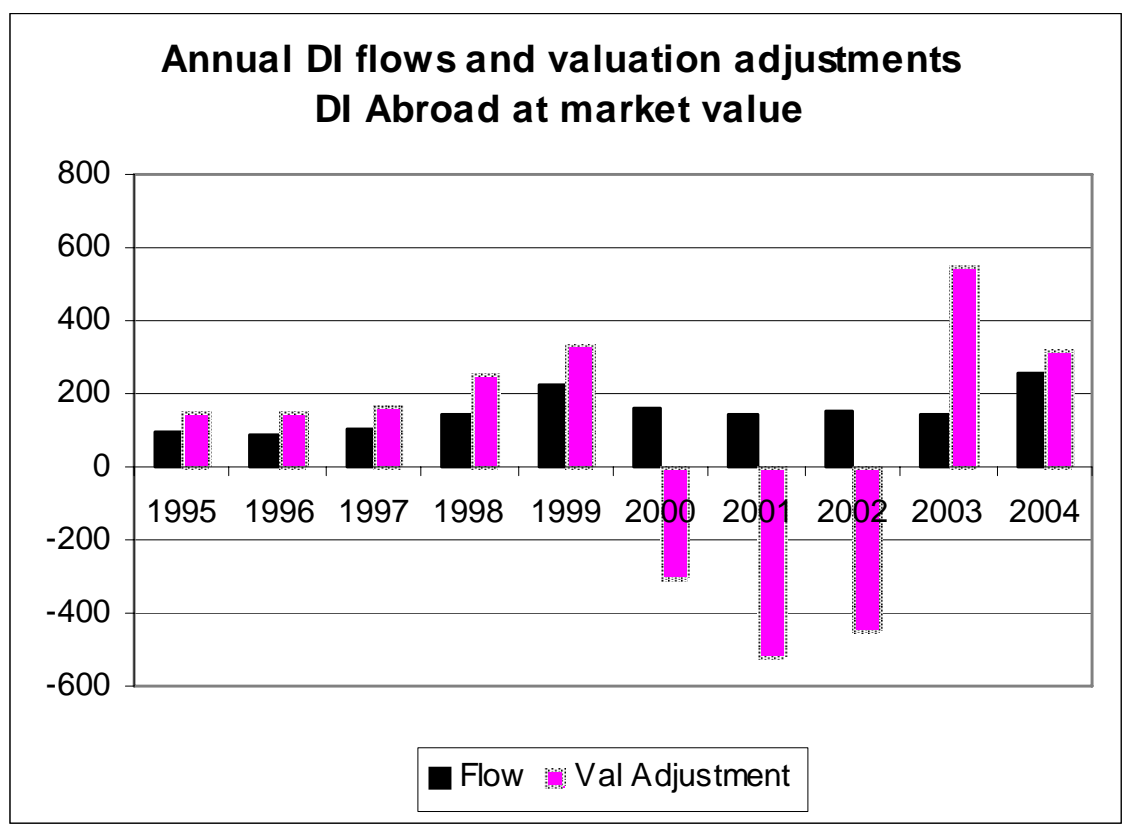

Figure 8

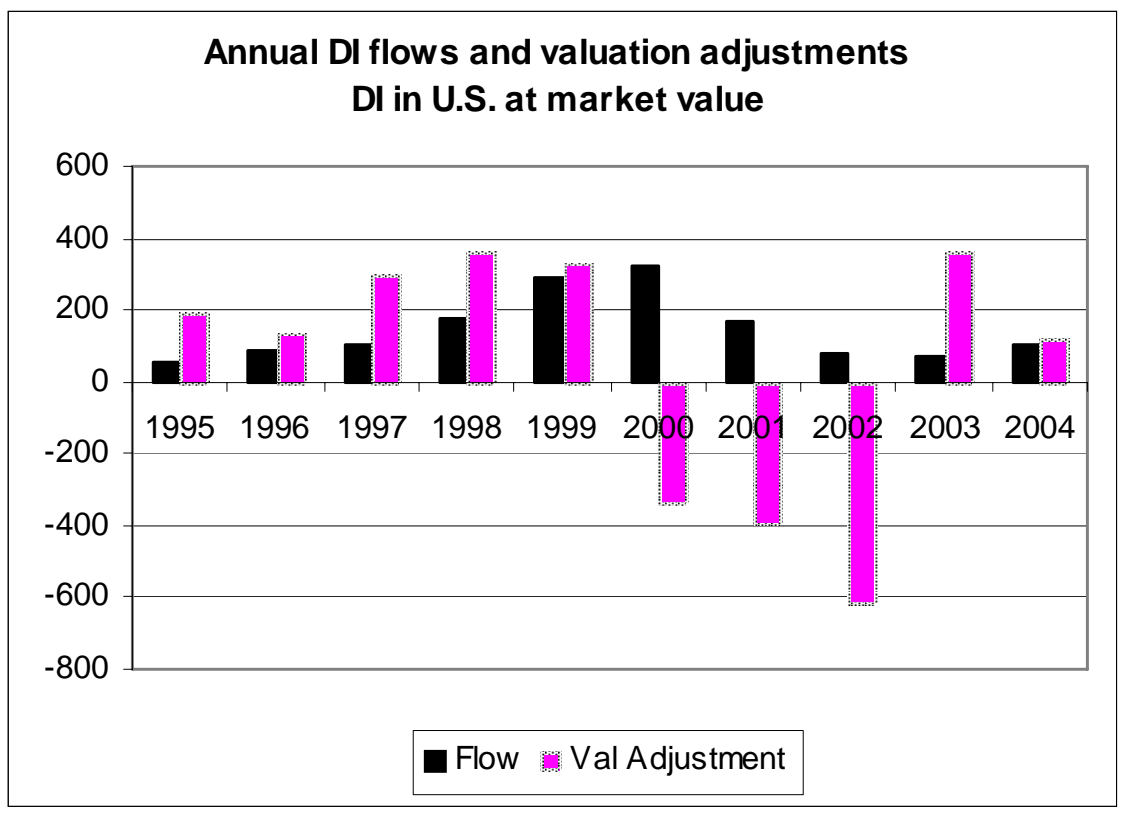

Figure 9 


\section{$3 \quad$ Modeling Valuation Rates}

The first step in modeling annual valuation adjustments is to define the valuation rates associated with each valuation method: current cost $(c c)$ and market value $(m v)$. For U.S. assets abroad, we define the valuation rate associated with ith measure ( $c c$ or $m v), R \alpha_{i t}^{a}$ as

$$
R \alpha_{i t}^{a}=\frac{\alpha_{i t}^{a}}{A_{i, t-1}^{a}}, i=c c, m v,
$$

where $\alpha_{i t}^{a}$ is BEA's annual nominal valuation adjustment for U.S. assets and $A_{i t}^{a}$ is BEA's annual nominal asset position in year $t$. The valuation rate for U.S. liabilities to foreign residents is

$$
R \lambda_{i t}^{a}=\frac{\lambda_{i t}^{a}}{L_{i, t-1}^{a}}, i=c c, m v
$$

where $\lambda_{i t}^{a}$ is the annual nominal valuation adjustment for U.S. liabilities to foreigners associated with the $i t h$ measure and $L_{i t}^{a}$ is the annual nominal liability position in year $t$.

The second step is to link these annual valuation rates to the factors BEA uses in its reported valuation adjustments. Specifically, BEA links $\alpha_{c c t}^{a}$ and $\lambda_{c c t}^{a}$ to movement in exchange rates and prices on tangible assets (such as property, plant, equipment and inventories); $\alpha_{m v t}^{a}$ and $\lambda_{m v t}^{a}$ are linked to movements in dollar-valued stock prices. The resulting equations are

$$
\begin{aligned}
& R \alpha_{i t}^{a}=\theta_{i} X_{i, t}^{a}+u_{i t}^{a}, i=c c, m v \\
& R \lambda_{i t}^{a}=\varphi_{i} X_{i, t}^{a}+v_{i t}^{a}, i=c c, m v,
\end{aligned}
$$

where $X_{i, t}^{a}$ is a vector of the variables used by BEA at an annual frequency. The next section selects the variables included in the $X_{i}^{\prime} s$ and estimates $\theta_{i}$ and $\varphi_{i}$ using OLS.

\subsection{U.S. DI Abroad at Current Cost}

Recall from section 2 that the valuation adjustment to DI abroad at current cost was dominated by movement in the exchange rate and prices of products. Thus we model the total valuation rates as

$$
R \alpha_{c c, t}^{a}=\alpha \frac{\Delta E_{t}}{E_{t-1}}+\beta \pi_{t}^{*}+u_{c c, t}^{a}
$$

where $E_{t}$ : is the DI-weighted effective value of the dollar, end of quarter

$\pi_{t}^{*}$ : is the DI-weighted foreign inflation (Q4/Q4), and

$u_{c c, t}^{a}$ : is the residual.

In constructing both $\frac{\Delta E_{t}}{E_{t-1}}$ and $\pi^{*}$ we use data from 19 foreign countries. Specifically, $\frac{\Delta E_{t}}{E_{t-1}}$ is the DIweighted sum of bilateral exchange rate growth rates, while $\pi^{*}$ is the DI-weighted sum of foreign CPI inflation rates. The weights vary over time, as the size of each country's year-end U.S. direct investment position varies relative to the total U.S. direct investment position abroad in these countries. Appendix 1 provides the list of countries used in these series construction.

We expect a dollar appreciation (an increase in $E$ ) to lower the current-cost value of U.S. assets abroad $(\alpha<0)$ and an increase in the foreign inflation rate to produce the opposite effect $(\beta>0)$. Ideally, $\alpha \frac{\Delta E_{t}}{E_{t-1}}$ should capture the exchange-rate component of the valuation rate, $\beta \pi_{t}^{*}$ should capture price adjustments, 
and $u_{c c, t}^{a}$ should represent factors not modeled explicitly.

Based on annual observations from 1976 to 2003, the estimation results confirm our priors (figure 10). ${ }^{4}$ The estimates indicate that a one percent appreciation of the dollar lowers the rate of current-cost valuation adjustments by about 0.5 percentage points; a one-percent increase in the foreign inflation rate raises the valuation rate by nearly 0.5 percentage points. The coefficient estimate on the exchange rate being less than one can be a result of many factors. First, some assets of the firms may be in dollars (as a matter of fact, some foreign affiliates keep their books in dollars). Second, firms use exchange rate hedges. Third, our DI-weighted dollar does not encompass all the recipients of U.S. direct investment, so that our independent variable is a proxy for the true exchange rate.

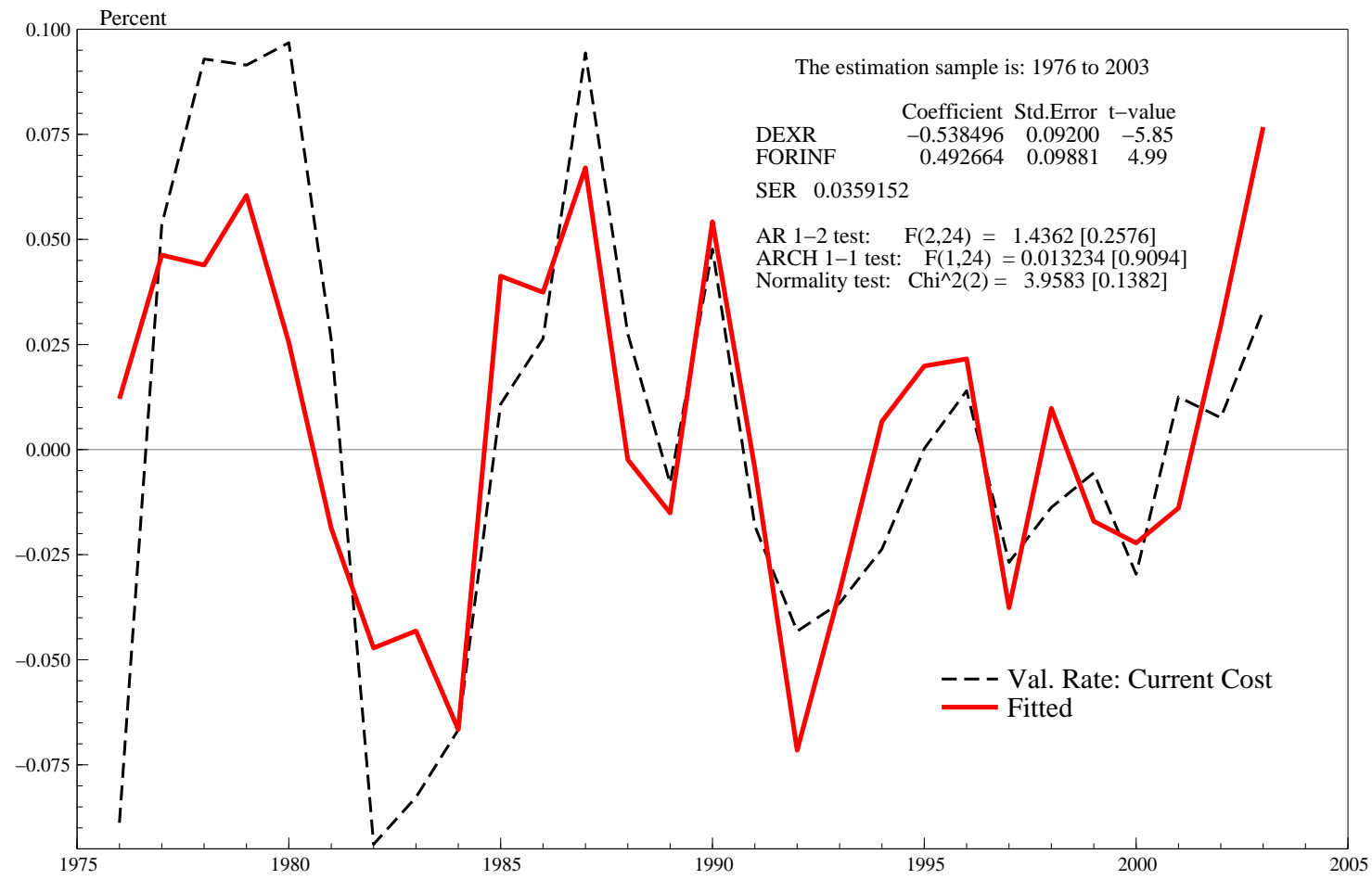

Figure 10 - Regression for the Valuation Adjustment Rate of U.S. DI Abroad at current cost.

As an alternative formulation, we augment equation (1) to include a role for intangible considerations, such as good will, that may be embodied in the "other" portion of the valuation adjustment. An example of goodwill is when a U.S. multinational purchases a foreign operation at a market value that is larger than its book value. ${ }^{5}$ We postulate that these intangibles are a fraction $\delta$ of the investment rate (flow/position):

$$
\text { goodwillRate }{ }_{c c, t}^{a}=\frac{\delta \cdot O_{t}^{a}}{A_{c c, t-1}^{a}}
$$

\footnotetext{
${ }^{4}$ The figure reports test results for the propertiess of the residuals: Serial Independence (AR1-2), homoskedasticity (ARCH 11), and Normality $\left(\mathrm{Chi}^{2}(2)\right)$. The entries in brackets denote the significance level needed to reject the associated null hypothesis.

${ }^{5}$ Here flows will reflect the market value of the purchase, but BEA backs out the difference between market and book value because valuation of nontangible assets is done on a book-value basis.
} 
Thus the empirical formulation becomes

$$
R \alpha_{c c, t}^{a}=\alpha \frac{\Delta E_{t}}{E_{t-1}}+\beta \pi_{t}^{*}+\theta \cdot \text { goodwillRate } e_{c c, t}^{a}+u_{c c, t}^{a} .
$$

Based on annual observations from 1976 to 2003, the estimation results suggest that our approach to modeling intangibles has no statistical effect on the valuation rate (figure 11). The estimates indicate that a one percent appreciation of the dollar lowers rate of current-cost valuation adjustments by 0.5 percentage points; a one-percent increase in the foreign inflation rate raises the valuation rate by 0.5 percentage points, about what one gets from the estimates of equation (1).

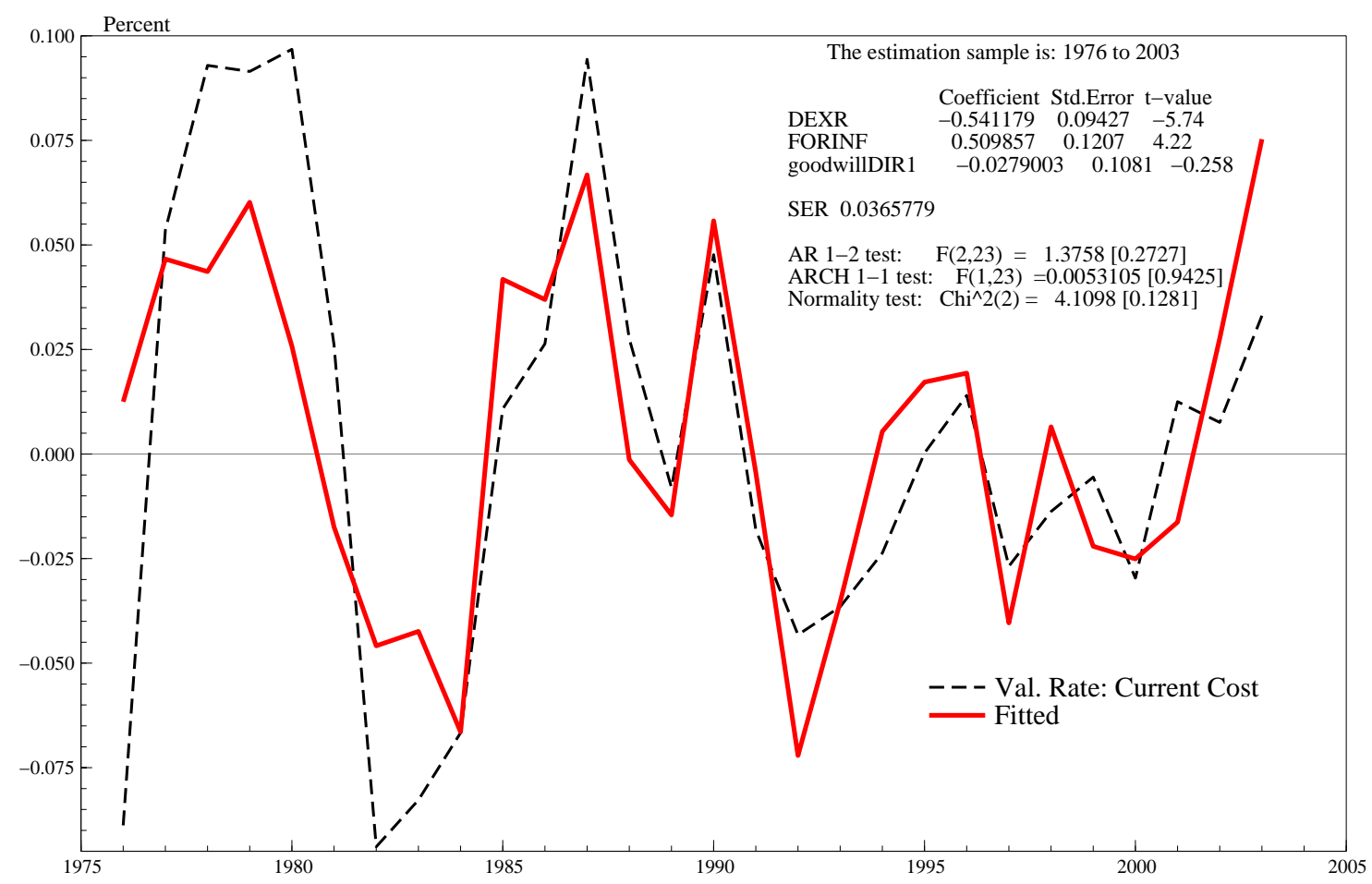

Figure 11 - Alternative Regression for the Valuation Adjustment Rate of U.S.DI Abroad at Current Cost.

\section{$3.2 \quad$ U.S. DI Abroad at Market Value}

BEA revalues the historical-cost value of equity in foreign affiliates of U.S. parents using a weighted average of foreign stock prices. Specifically, BEA uses a weighted average of individual Morgan Stanley stock indexes for countries with relatively large U.S. DI positions, and a world index, excluding the United States, to proxy for movements in other countries' stock markets. With these considerations in mind, we postulate that

$$
R \alpha_{m v, t}^{a}=\eta \frac{\Delta F S M_{t}}{F S M_{t-1}}+u_{m v, t}^{a},
$$

where FSM is a yearend DI-weighted average of foreign stock-market index expressed in US dollars. Implicit in this formulation is that movements in the bilateral exchange rates and foreign stock markets affect the 
valuation adjustment homogeneously. ${ }^{6}$ To construct this series we use 20 individual country stock market series, as well as the Morgan Stanley ROW, excluding the United States, stock market index. BEA uses individual country stock market indexes for the countries with relatively large shares of U.S. DI and then proxies the remaining countries' stock market valuations with the Morgan Stanley index. ${ }^{7}$ Appendix 1 provides more details.

We expect that an increase in the dollar value of the foreign-stock market to raise the market value of U.S. assets abroad $(\eta>0)$. The results confirm this expectation (figure 12): a one-percent increase in the foreign stock market raises the valuation rate by three-fourths. Recall that our stock market variable is measured in dollars, so this $3 / 4$ estimate combines the true stock market effect with the dollar effect, where we found a less than 1:1 impact from movement in the dollar on the current cost valuation rate.

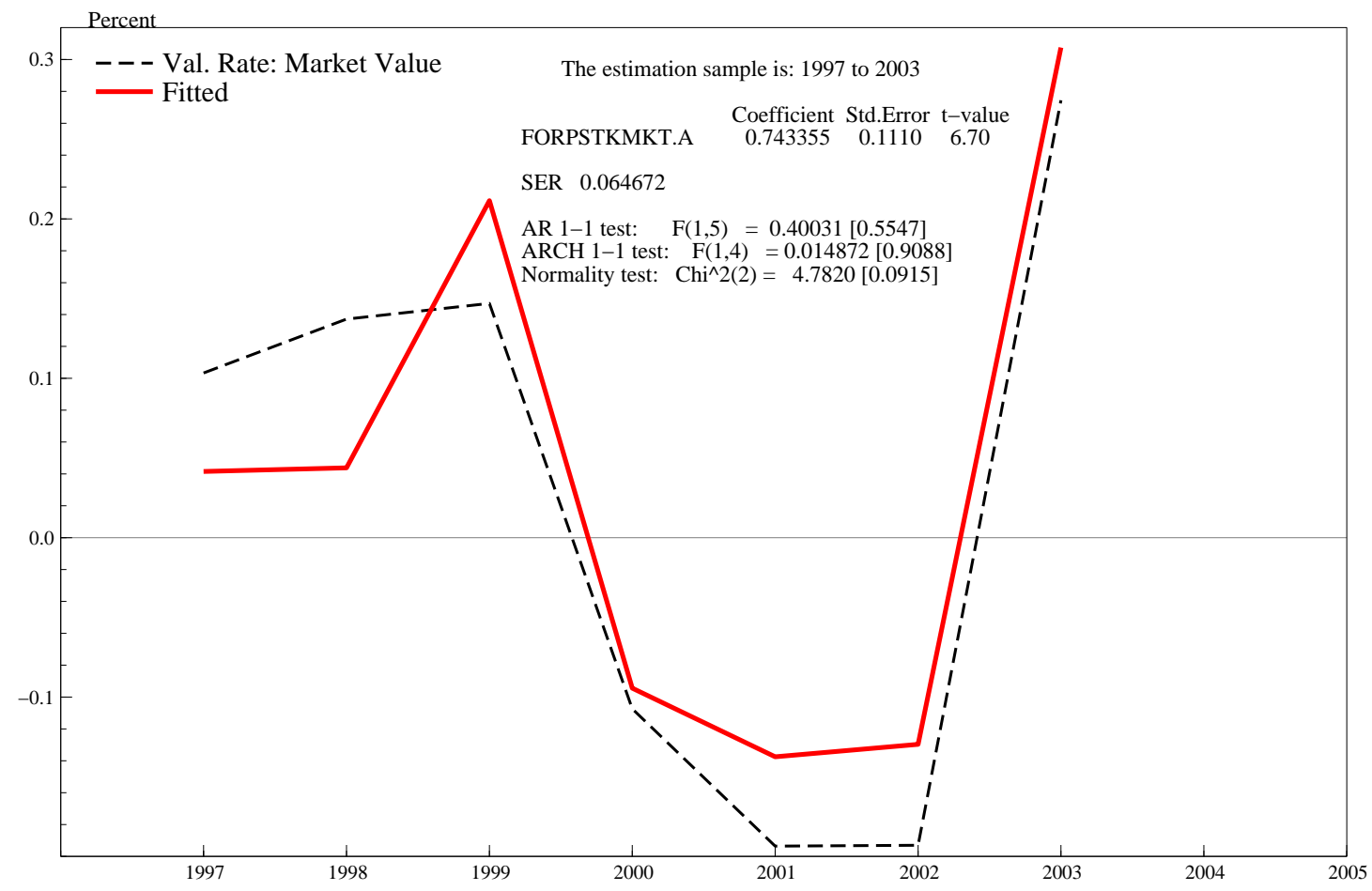

Figure 12 - Regression for the Valuation Adjustment Rate of U.S. DI Abroad at Market Value.

\subsection{DI in the United States at Current Cost}

As noted in section 2, when discussing the components of the valuation adjustments, the role of the exchange rate on valuation adjustments for DI in the United States is negligible. As a result, we focus on price adjustments in the valuation model. Specifically, we postulate that

$$
R \lambda_{c c, t}^{a}=\rho \pi_{t}+v_{c c, t}^{a}
$$

\footnotetext{
${ }^{6} \mathrm{BEA}$ reports exchange rate and price effects separately. We do not disentangling these two effects.

${ }^{7}$ Since the Morgan Stanley world, excluding the United States, index begins in mid-1996, our annual FSM only has observations beginning in 1997 .
} 
where $\pi_{t}$ is the inflation rate of the nonresidential business fixed investment deflator (Q4/Q4) and $u_{c c, t}^{l}$ is the residual. ${ }^{8}$ Our expectation is for an increase in the U.S. inflation rate to raise the current cost of U.S. liabilities to foreigners $(\rho>0)$. Based on annual observations from 1973 to 2003, the estimation results confirm this expectation (figure 13). A one-percent inflation rate in nonresidential business fixed investment in the United States translates into a 8/10 percent increase in the valuation rate. This coefficient estimate is not statistically different from one.

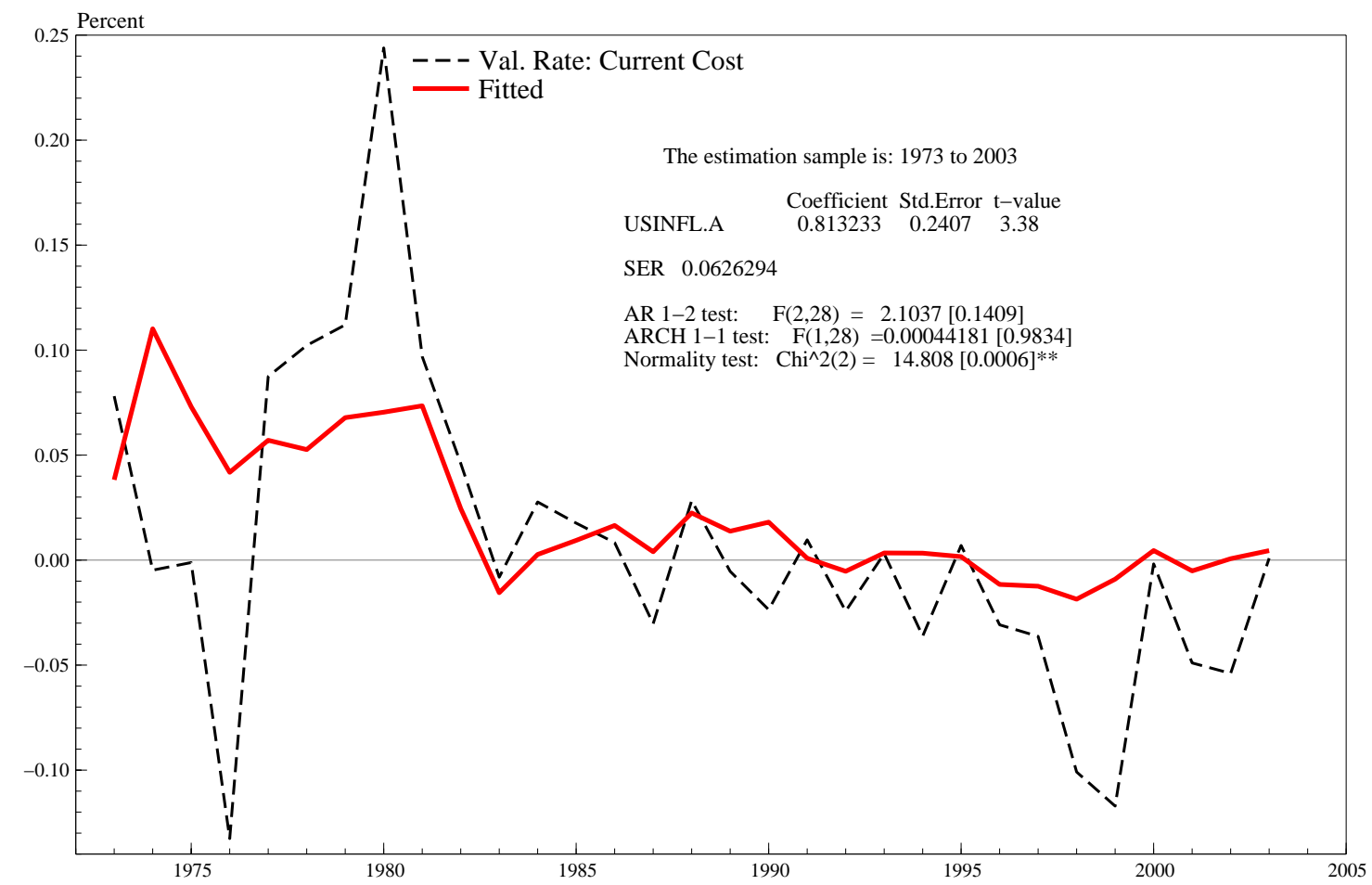

Figure 13 - Regression for the Valuation Adjustment Rate of DI in the U.S. at Current Cost.

We also consider the alternative formulation for the valuation rate where we augment equation (3) to include a role for intangibles. We postulate that these intangibles are a fraction of the investment rate:

$$
\text { goodwillRate }_{c c, t}^{l}=\frac{\delta \cdot I_{t}}{L_{c c, t-1}}
$$

so that

$$
R \lambda_{c c, t}^{a}=\rho \pi_{t}+\theta \cdot \text { goodwillRate }{ }_{c c, t}^{l}+v_{c c, t}^{a} .
$$

Based on annual observations from 1973 to 2003, the estimation results suggest that our approach to modeling intangibles has no statistical effect on the valuation rate (figure 14).

\footnotetext{
${ }^{8} \mathrm{CPI}$ inflation is not a significant factor in explaining the valuation adjustment associated with DI in the United States at current cost.
} 


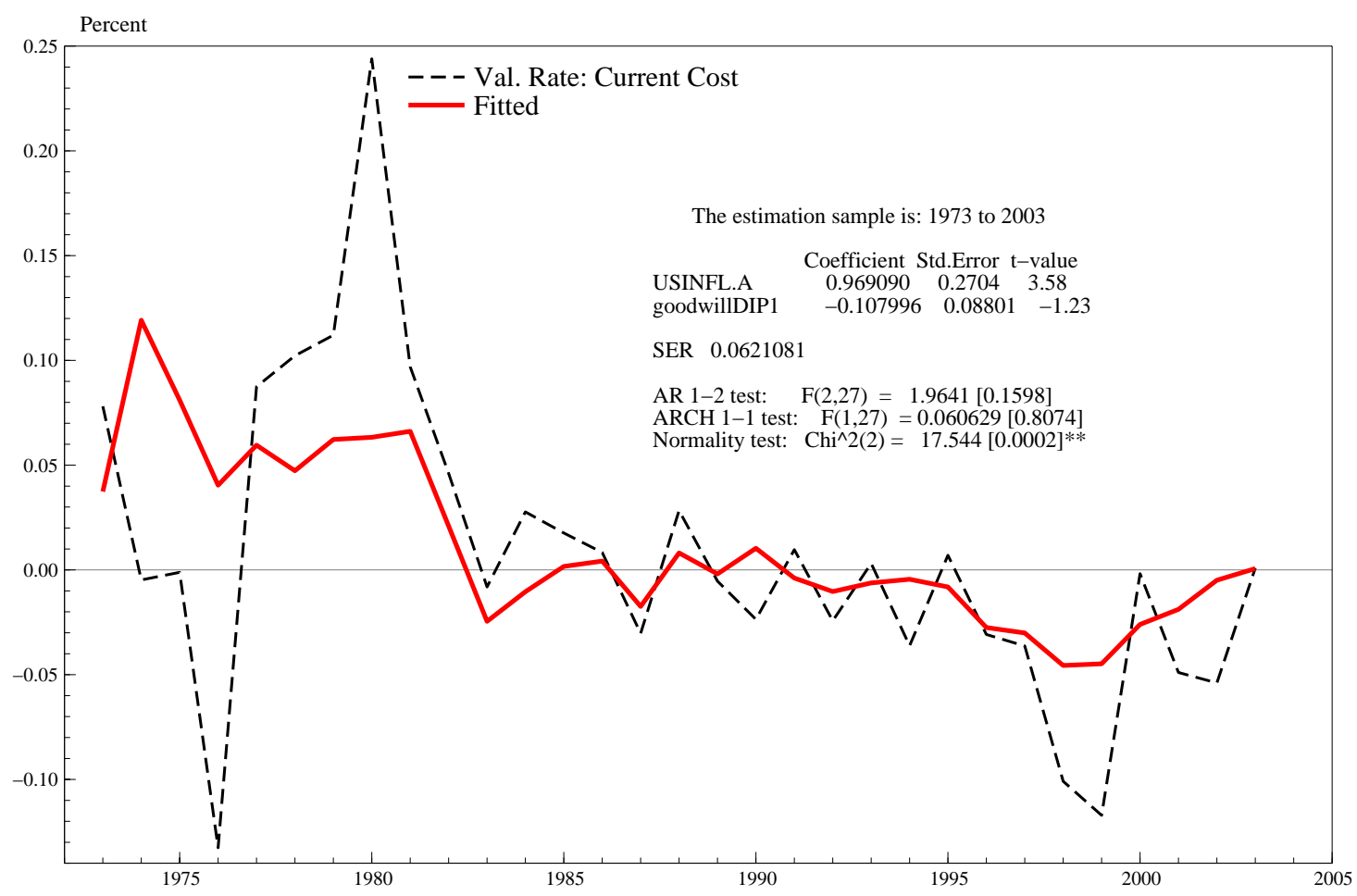

Figure 14 - Alternative Regression for the Valuation Adjustment Rate of U.S. DI Abroad at Current Cost.

\subsection{DI in the United States at Market Value}

BEA's market value valuation adjustment uses the Standard and Poor's 500 index to revalue the historicalcost value of equity in U.S. affiliates of foreign parents. Since the revaluation of (stock) prices is the key factor influencing the valuation adjustment, we mimic BEA's analysis by postulating that

$$
R \lambda_{m v, t}^{a}=\gamma \frac{\Delta S M_{t}}{S M_{t-1}}+v_{m v, t}^{a}
$$

where $S M$ is the end of year value of the Standard and Poor 500 index. We expect that an increase in the U.S. stock market will raise the value of U.S. external liabilities $(\gamma>0)$. Based on data from 1982 to 2003, the results confirm this expectation (figure 15). Also, an increase in the U.S. stock market translates into a nearly proportional increase in the valuation rate. Notice that the regression has a tight fit over the past decade. 


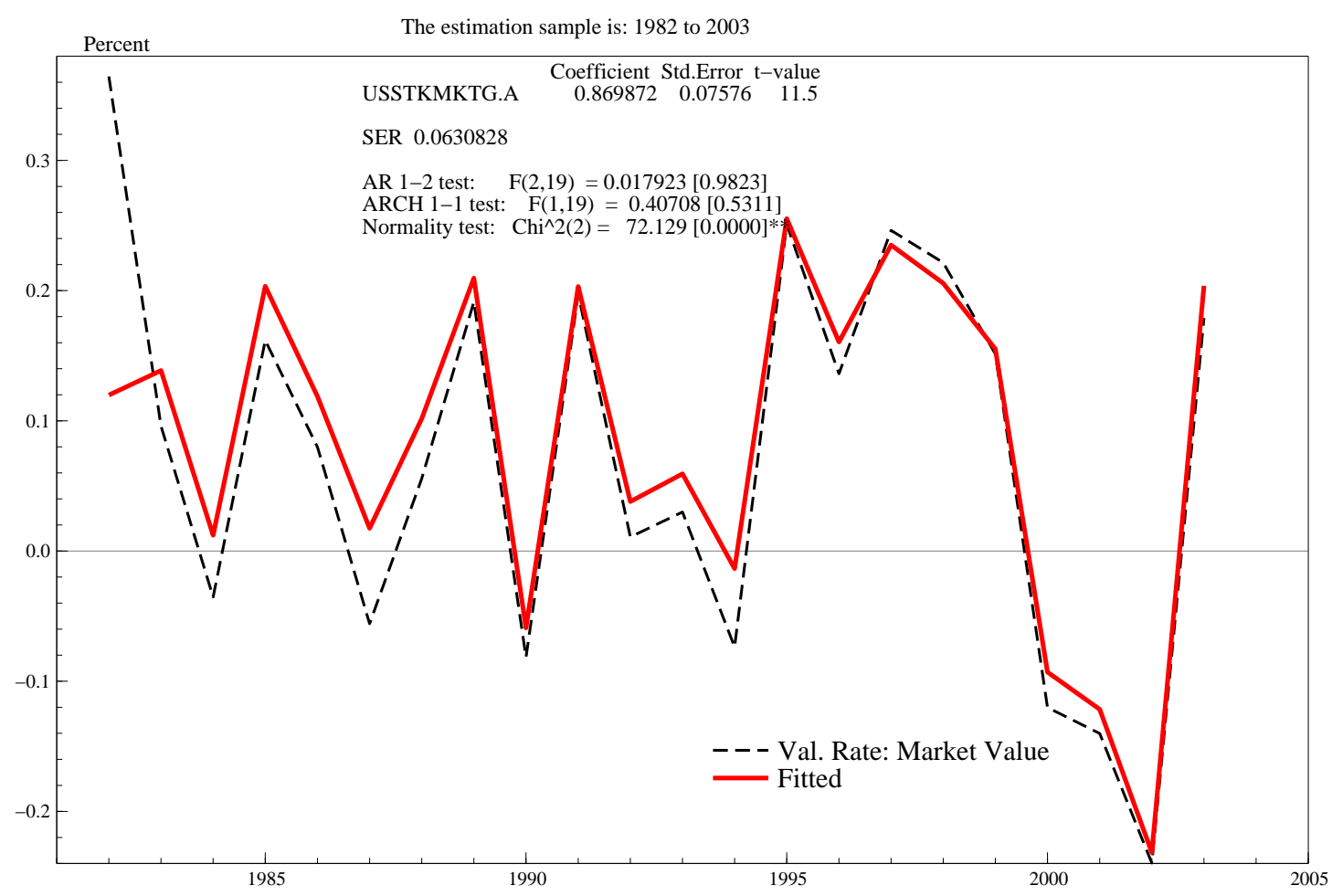

Figure 15 - Regression for the Valuation Adjustment Rate of DI in the U.S. at Market Value.

As an alternative formulation, we augment equation (4) to include a role for intangibles. Specifically, we postulate that these intangible considerations are a fraction of the investment rate:

$$
\text { goodwillRate }{ }_{m v, t}^{l}=\frac{\delta \cdot I_{t}}{L_{m v, t-1}}
$$

so that

$$
R \lambda_{m v, t}^{a}=\beta \pi_{t}+\theta \cdot \text { goodwillRate }{ }_{m v, t}^{l}+v_{m v, t}^{a} .
$$

Based on annual observations from 1973 to 2003, the estimation results suggest that our approach to modeling intangibles has no statistical effect on the valuation rate (figure 16). The estimates indicate that a one percent rise in the U.S. stock market raises proportionally the valuation rate for market value. 


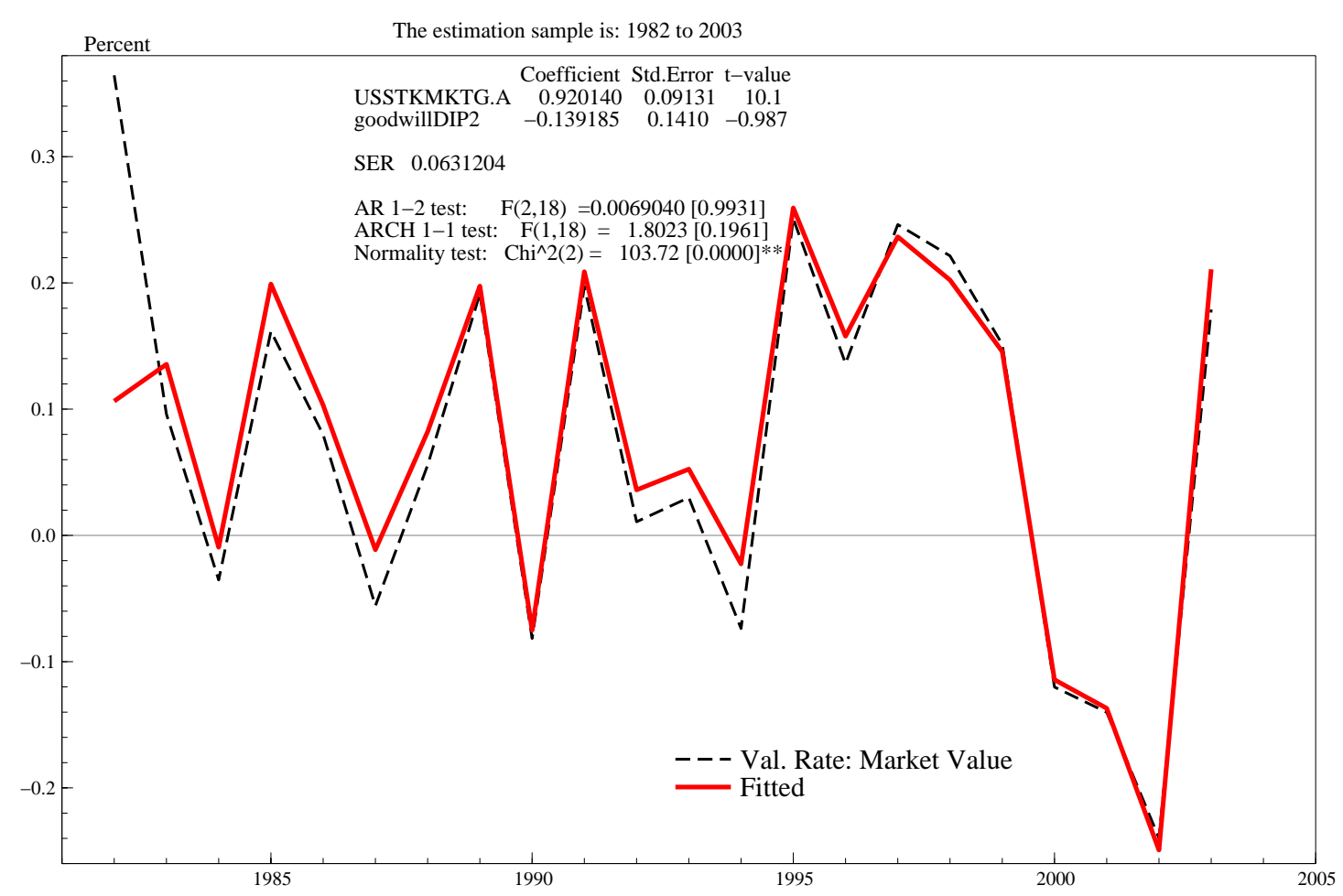

Figure 16 - Alternative Regression for the Valuation Adjustment Rate of DI in the U.S. at Market Value.

\section{Positions and Valuation Adjustments: Annual and Quarterly Frequencies}

\subsection{Method}

Recall from section 2 that BEA offers annual data for three measures of the U.S. DI position abroad and three measures of the DI position in the United States. These measures differ in the manner in how the stocks are valued: historical cost $(h)$, current cost $(c c)$, and market value $(m v)$. The annual positions positions at current cost and market value are constructed as

$$
\begin{aligned}
& A_{i t}^{a}=A_{i, t-1}^{a}+O_{t}^{a}+\alpha_{i t}^{a}, i=c c, m v \\
& L_{i t}^{a}=L_{i, t-1}^{a}+I_{t}^{a}+\lambda_{i t}^{a}, i=c c, m v
\end{aligned}
$$

where $A_{i t}^{a}$ is the annual asset position in year $t$ associated with $i t h$ measure ( $c c$ or $m v$ ); $L_{i t}^{a}$ is the annual liability position in year $t ; I_{t}^{a}$ is the annual inflow of direct investment; $O_{t}^{a}$ is the annual outflow of direct investment; $\alpha_{i t}^{a}$ is the annual valuation adjustment for U.S. assets abroad and $\lambda_{i t}^{a}$ is the annual valuation adjustment for U.S. liabilities to foreigners associated with the $i t h$ measure. ${ }^{9}$ Substituting in our model

\footnotetext{
${ }^{9}$ DI positions at historic cost also have valuation adjustments for realized capital gains. But, these are minimal adjustments compared to those for current cost and market value.
} 
estimates for the valuation rates, we rewrite these equations as

$$
\begin{aligned}
& A_{i t}^{a}=A_{i, t-1}^{a}+O_{t}^{a}+R \alpha_{i t}^{a} \cdot L_{i, t-1}^{a}, i=c c, m v \\
& L_{i t}^{a}=L_{i, t-1}^{a}+I_{t}^{a}+R \lambda_{i t}^{a} \cdot L_{i, t-1}^{a}, i=c c, m v,
\end{aligned}
$$

where

$$
\begin{aligned}
R \alpha_{i t}^{a} & =\frac{\alpha_{i t}^{a}}{A_{i, t-1}^{a}}=\theta_{i} X_{i, t}^{a}+u_{i t}^{a}, i=c c, m v \\
R \lambda_{i t}^{a} & =\frac{\lambda_{i t}^{a}}{L_{i, t-1}^{a}}=\varphi_{i} X_{i, t}^{a}+v_{i t}^{a}, i=c c, m v
\end{aligned}
$$

To generate quarterly valuation adjustments from these annual estimates, we apply a two-step procedure. First, we use the estimates of $\theta_{i}$ and $\varphi_{i}$ to generate a first round of quarterly estimates of the valuation rates. This task involves applying the coefficient estimates to quarterly data:

$$
\begin{aligned}
\widehat{R \alpha}_{i t}^{q} & =\widehat{\theta}_{i} \cdot X_{i, t}^{q}+\widehat{u}_{i t}^{q} \\
\widehat{R \lambda}_{i t}^{q} & =\widehat{\varphi}_{i} \cdot X_{i, t}^{q}+\widehat{v}_{i t}^{q}
\end{aligned}
$$

where $X_{t}^{q}$ is the quarterly counterpart of $X_{t}^{a}$. First round of quarterly positions are constructed using the first round valuation adjustments. These are

$$
\begin{aligned}
& \widehat{A}_{i t}^{q}=\widehat{A}_{i t}^{q-1}+O_{i t}^{q}+\widehat{\alpha}_{i t}^{q}=\widehat{A}_{i t}^{q-1}+O_{i t}^{q}+\widehat{R \alpha}_{i t}^{q} \cdot \widehat{A}_{i t}^{q-1} \\
& \widehat{L}_{i t}^{q}=\widehat{L}_{i t}^{q-1}+I_{i t}^{q}+\widehat{\lambda}_{i t}^{q}=\widehat{L}_{i t}^{q-1}+I_{i t}^{q}+\widehat{R \lambda}_{i t}^{q} \cdot \widehat{L}_{i t}^{q-1} .
\end{aligned}
$$

Notice that the above equations generate the level of the quarterly valuation adjustments endogenously. To ensure full consistency between the published annual positions and our quarterly estimates for the fourth quarter a second step is needed.

We define an iteration error for quarter $q$ of year $t$ as

$$
e_{i t}^{q}=\frac{\alpha_{i t}^{a}-\Sigma_{q} \widehat{\alpha}_{i t}^{q}}{4}
$$

where annual data for $\alpha_{i t}^{a}$ are available from the BEA. With this approximation error we generate a second round of quarterly valuation adjustments and positions as

$$
\begin{aligned}
& \widehat{\widehat{\alpha}}_{i t}^{q}=\widehat{\alpha}_{i t}^{q}+e_{i t}^{q}=\widehat{R \alpha}_{i t}^{q} \cdot \widehat{A}_{i t}^{q-1}+e_{i t}^{q} \\
& \widehat{\widehat{A}}_{i t}^{q}=\widehat{\widehat{A}}_{i t}^{q-1}+O_{t}^{q}+\widehat{\widehat{\alpha}}_{i t}^{q} .
\end{aligned}
$$

As shown in Appendix 2, this second round of quarterly positions is fully consistent with BEA's annual data: $\widehat{\hat{A}}_{i t}^{4}=A_{i t}^{a}$.

We now turn to estimating quarterly positions. 


\subsection{Results}

We estimate quarterly DI positions at current cost $(c c)$ and market value $(m v)$ for DI claims and liabilities. We create a given year's quarter positions by taking BEA's previous year-end DI position and adding the reported quarterly flows and add our quarterly valuation adjustments. In this procedure we ensure our Q4 position matches BEA's reported year-end position as noted above.

Table 1 provides the quarterly DI capital stocks, flows and total valuation adjustments over time for both the current cost and market value for DI Abroad. The fourth quarter capital stock is the same value as BEA's yearend value, and the sum of the four quarter valuation adjustments equals BEA's annual valuation adjustment. The valuation adjustment at current cost, on average, equals 35 percent, in absolute value, of the flow. At market value, the valuation adjustment is nearly 350 percent of the average flow in absolute value, with large positive and negative swings in the adjustment over time.

Table 2 provides the quarterly DI capital stock, flows and total valuation adjustments over time for both the current cost and market value for DI in the United States. Again, the fourth quarter capital stock is the same value as BEA's annual value, and the sum of the four quarter valuation adjustments equals BEA's annual valuation adjustment. The valuation adjustment at current cost, on average, equals 45 percent, in absolute value, of the flow. At market value, the valuation adjustment is over 600 percent of the average flow, with large positive and negative swings in the adjustment over time.

The data presented here are for historical positions, flows and valuation adjustments. The next section uses the valuation models to look into possible future paths of these series.

\section{Asset-price Shocks and the Net Direct Investment Position}

Now that we have an empirical model for the valuation rates, we can estimate the effect of future changes in asset prices on the net direct investment position $(N D I P)$. We consider changes in the inflation rates (U.S. and foreign), in the returns on the stock markets (U.S. and foreign) and in the exchange rate. We quantify the effect of a change each of these asset prices, individually, on the NDIP, for both the current cost and market value valuation. We begin, in the first subsection, by providing rules of thumb for the immediate impact of an asset price change on the NDIP. We find potentially large impacts on the NDIP from what might be considered small asset price shocks. In addition, a one-time shock to a asset price affects not only the immediate valuation adjustment and position but, as we show in the following subsection, there are long-term implications for the positions as well.

\subsection{Short-run Effect}

The model associated with the current-cost valuation is

$$
\begin{aligned}
N D I P_{c c, t} & =A_{c c, t}-L_{c c, t} \\
A_{c c, t} & =A_{c c, t-1}+O_{t}+R \alpha_{c c, t} \cdot A_{c c, t-1} \\
L_{c c, t} & =L_{c c, t-1}+I_{t}+R \lambda_{c c, t} \cdot L_{c c, t-1} \\
R \alpha_{c c, t} & =\alpha \widehat{E}_{t}+\beta \pi_{t}^{*} \\
R \lambda_{c c, t} & =\rho \pi_{t}
\end{aligned}
$$


TABLE 1 - Direct Investment Abroad

\begin{tabular}{|c|c|c|c|c|c|c|c|c|c|}
\hline \multirow{3}{*}{ year } & \multirow[b]{3}{*}{ quarter } & \multicolumn{4}{|c|}{ 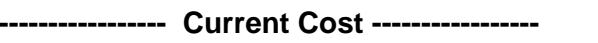 } & \multicolumn{4}{|c|}{---------------- Market Value --------------- } \\
\hline & & KS & $\Delta \mathrm{KS}$ & Flow & Total VA & KS & $\Delta \mathrm{KS}$ & Flow & Total VA \\
\hline & & \multicolumn{4}{|c|}{ million $\$$} & \multicolumn{4}{|c|}{ million $\$$} \\
\hline 1995 & 1 & 815874 & 29309 & 21684 & 7625 & 1139108 & 24526 & 21684 & 2842 \\
\hline 1995 & 2 & 834522 & 18648 & 16033 & 2615 & 1220437 & 81329 & 16033 & 65296 \\
\hline 1995 & 3 & 856147 & 21625 & 23023 & -1398 & 1293126 & 72689 & 23023 & 49666 \\
\hline 1995 & 4 & 885506 & 29359 & 38010 & -8651 & 1363792 & 70666 & 38010 & 32656 \\
\hline 1996 & 1 & 911539 & 26033 & 26732 & -699 & 1422439 & 58647 & 26732 & 31915 \\
\hline 1996 & 2 & 927258 & 15719 & 16828 & -1109 & 1464040 & 41601 & 16828 & 24773 \\
\hline 1996 & 3 & 954129 & 26871 & 24803 & 2068 & 1508900 & 44860 & 24803 & 20057 \\
\hline 1996 & 4 & 989810 & 35681 & 23522 & 12159 & 1608340 & 99440 & 23522 & 75918 \\
\hline 1997 & 1 & 1010110 & 20300 & 32669 & -12369 & 1682659 & 74319 & 32669 & 41650 \\
\hline 1997 & 2 & 1037967 & 27858 & 27385 & 473 & 1862069 & 179410 & 27385 & 152025 \\
\hline 1997 & 3 & 1056033 & 18066 & 23369 & -5303 & 1950936 & 88867 & 23369 & 65498 \\
\hline 1997 & 4 & 1068063 & 12030 & 21380 & -9350 & 1879285 & -71651 & 21380 & -93031 \\
\hline 1998 & 1 & 1111160 & 43097 & 45257 & -2160 & 2166972 & 287687 & 45257 & 242430 \\
\hline 1998 & 2 & 1148095 & 36935 & 46885 & -9950 & 2180745 & 13773 & 46885 & -33112 \\
\hline 1998 & 3 & 1172812 & 24717 & 22958 & 1759 & 1962382 & -218362 & 22958 & -241320 \\
\hline 1998 & 4 & 1196021 & 23209 & 27544 & -4335 & 2279601 & 317219 & 27544 & 289675 \\
\hline 1999 & 1 & 1248491 & 52470 & 72236 & -19766 & 2362913 & 83312 & 72236 & 11076 \\
\hline 1999 & 2 & 1298687 & 50196 & 52259 & -2063 & 2480043 & 117130 & 52259 & 64871 \\
\hline 1999 & 3 & 1381643 & 82956 & 66765 & 16191 & 2497631 & 17589 & 66765 & -49176 \\
\hline 1999 & 4 & 1414355 & 32712 & 33674 & -962 & 2839639 & 342008 & 33674 & 308334 \\
\hline 2000 & 1 & 1440131 & 25776 & 38510 & -12734 & 2881115 & 41476 & 38510 & 2966 \\
\hline 2000 & 2 & 1475532 & 35401 & 55407 & -20006 & 2846239 & -34876 & 55407 & -90283 \\
\hline 2000 & 3 & 1496762 & 21230 & 42712 & -21482 & 2767259 & -78981 & 42712 & -121693 \\
\hline 2000 & 4 & 1531607 & 34845 & 22583 & 12262 & 2694014 & -73245 & 22583 & -95828 \\
\hline 2001 & 1 & 1543441 & 11834 & 39909 & -28075 & 2425740 & -268274 & 39909 & -308183 \\
\hline 2001 & 2 & 1588715 & 45274 & 30410 & 14864 & 2436060 & 10320 & 30410 & -20090 \\
\hline 2001 & 3 & 1658125 & 69410 & 47370 & 22040 & 2231788 & -204272 & 47370 & -251642 \\
\hline 2001 & 4 & 1693131 & 35006 & 24660 & 10346 & 2314934 & 83146 & 24660 & 58486 \\
\hline 2002 & 1 & 1718716 & 25585 & 51746 & -26161 & 2345468 & 30534 & 51746 & -21212 \\
\hline 2002 & 2 & 1791898 & 73182 & 39655 & 33527 & 2239402 & -106066 & 39655 & -145721 \\
\hline 2002 & 3 & 1810512 & 18614 & 36755 & -18141 & 1913123 & -326279 & 36755 & -363034 \\
\hline 2002 & 4 & 1860418 & 49906 & 26304 & 23602 & 2022588 & 109465 & 26304 & 83161 \\
\hline 2003 & 1 & 1884847 & 24429 & 20065 & 4364 & 1934927 & -87661 & 20065 & -107726 \\
\hline 2003 & 2 & 1966235 & 81388 & 48195 & 33193 & 2262345 & 327418 & 48195 & 279223 \\
\hline 2003 & 3 & 1995223 & 28989 & 43413 & -14424 & 2400031 & 137686 & 43413 & 94273 \\
\hline 2003 & 4 & 2062551 & 67328 & 28906 & 38422 & 2718203 & 318172 & 28906 & 289266 \\
\hline 2004 & 1 & 2115541 & 52990 & 55821 & -2831 & 2820170 & 101967 & 55821 & 46146 \\
\hline 2004 & 2 & 2146824 & 31283 & 63323 & -32040 & 2815277 & -4893 & 63323 & -68216 \\
\hline 2004 & 3 & 2212984 & 66161 & 43606 & 22555 & 2904706 & 89428 & 43606 & 45822 \\
\hline 2004 & 4 & 2367386 & 154402 & 89262 & 65140 & 3287373 & 382667 & 89262 & 293405 \\
\hline
\end{tabular}


Table 2 - Direct Investment in the United States

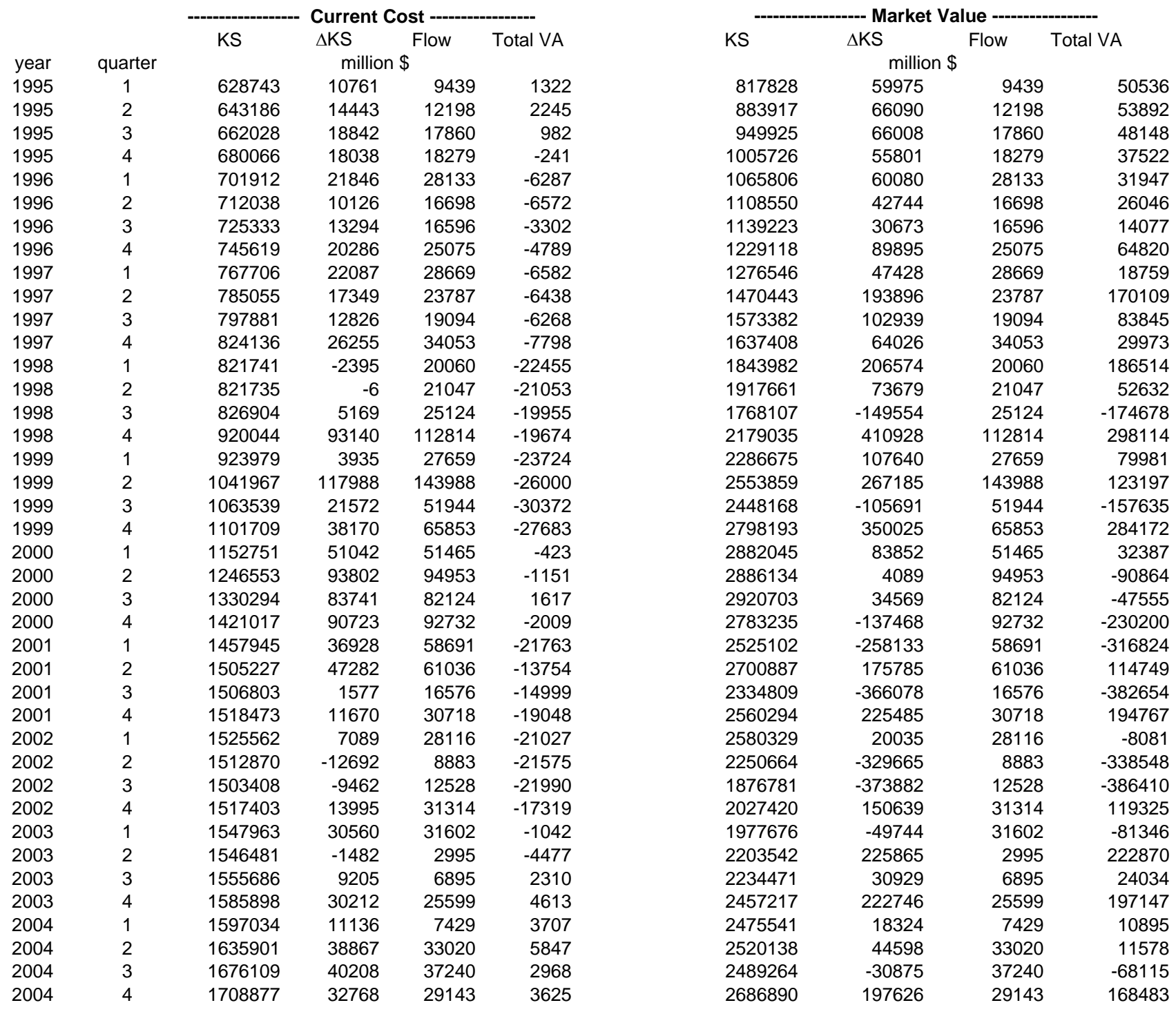


where $\widehat{E}_{t}=\frac{\Delta E_{t}}{E_{t-1}}$. To quantify the full effect of a change in the exchange rate or inflation rate on the net position needs to recognize that both valuation rates and direct-investment flows might be affected. For this analysis, however, we abstract from the response of direct investment flows because our focus is on the importance of valuation effects. In other words, we assume that $\Delta O=\Delta I=0 .{ }^{10}$ With this understanding, the change in the current cost net position is

$$
\begin{aligned}
\Delta N D I P_{c c, t} & =A_{c c, t-1} \cdot \Delta R \alpha_{c c, t}-L_{c c, t-1} \cdot \Delta R \lambda_{c c, t} \\
& =A_{c c, t-1} \cdot\left(\alpha \cdot \Delta \widehat{E}_{t}+\beta \cdot \Delta \pi_{t}^{*}\right)-L_{c c, t-1} \cdot \rho \cdot \Delta \pi_{t} .
\end{aligned}
$$

The data needed to quantify the short-run effect is given below:

\begin{tabular}{ll}
\hline Parameter Estimates & Initial Values (\$bil) \\
$\alpha=-0.54 \quad \rho=0.81$ & \\
$\beta=0.49$ & $A_{c c}=2367 \quad L_{c c}=1709$ \\
\hline
\end{tabular}

The values of $\alpha, \beta$ and $\rho$ are our model estimates, while the position data are BEA's end-2004 values. With these estimates, the short-run response of the net position to alternative shocks is given below:

\begin{tabular}{lcccc}
\hline Factor & Shock & \multicolumn{3}{c}{ Valuation Effect on NDIP } \\
\cline { 3 - 5 } & & Mathematical & Dollar Value (\$bil) & Relative to Stock (\%) \\
U.S. Inflation & $\Delta \pi=0.01$ & $-L_{c c} \cdot \rho \cdot \Delta \pi$ & -13.8 & -0.8 \\
Foreign Inflation & $\Delta \pi^{*}=0.01$ & $A_{c c} \cdot \beta \cdot \Delta \pi^{*}$ & 11.6 & 0.5 \\
Exchange Rate & $\Delta \widehat{E}=0.01$ & $A_{c c} \cdot \alpha \cdot \Delta \widehat{E}$ & -12.8 & -0.5 \\
\hline
\end{tabular}

The estimates reveal that relatively small changes in inflation and exchange rates translate into nontrivial valuation effects. If U.S. (foreign) inflation rose by one percent, then the NDIP would fall (rise) by nearly $\$ 14$ billion ( $\$ 12$ billion), or nearly $1(1 / 2)$ percent of the net position. A one percent appreciation in the dollar reduces the NDIP by roughly $\$ 13$ billion, or $1 / 2$ percent of the net position. Intuitively, the small changes in the valuation rates are being applied to large stocks of direct investment, which gives rise to large nominal valuation effects.

The results also reveal the potential for mutually offsetting effects. For example, if U.S. and foreign inflation increase simultaneously by one percentage point, then there is a decline in the net position of only $\$ 2$ billion, a relatively small magnitude. Further, if the foreign inflation remains constant but a one percentage point increase in the U.S. inflation rate is accompanied by a one-percent depreciation of the dollar $(\Delta \widehat{E}=-0.01)$, then the combined valuation effects lower the net position by roughly $\$ 1$ billion.

These results can be considered rules of thumbs to use in conjunction with other experiments with asset price shocks. For example, some argue the dollar needs to depreciate 10 percent to 20 percent to improve the U.S. current account balance (see Bergsten and Williamson, 2004, for an overview of economists' estimates of dollar depreciation). Taking the larger figure implies that the NDIP will increase by $\$ 255$ billion, or 10 percent of the net position. Of course, U.S. inflation may rise during this episode that, as noted above, could offset some of the impact of the dollar depreciation on the net position.

\footnotetext{
${ }^{10}$ If one believes that flows are also affected by the asset price shock, then one should consider our results as a bound on the total effect on the NDIP.
} 
We carry out the same calculations for the market-value valuation method; the associated model is

$$
\begin{aligned}
N D I P_{m v, t} & =A_{m v, t}-L_{m v, t} \\
A_{m v, t} & =A_{m v, t-1}+O_{t}+R \alpha_{m v, t} \cdot A_{m v, t-1} \\
L_{m v, t} & =L_{m v, t-1}+I_{t}+R \lambda_{m v, t} \cdot L_{m v, t-1} \\
R \alpha_{m v, t} & =\eta \cdot \widehat{F S M}_{t} \\
\widehat{F S M}_{t} & =\widehat{F S M}_{t}^{*}-\Delta \widehat{E}_{t} \\
R \lambda_{m v, t} & =\gamma \cdot \widehat{S M}_{t}
\end{aligned}
$$

where $\widehat{F S M}_{t}^{*}=\frac{\Delta F S M_{t}}{F S M_{t-1}}$ and $\widehat{S M}_{t}=\frac{\Delta S M_{t}}{S M_{t-1}}$. Again, with the understanding that what we want is to isolate the role of valuation effects on their own, we assume that direct investment flows are exogenously given. The resulting change in the net position is then given by

$$
\begin{aligned}
\Delta N D I P_{m v, t} & =A_{m v, t-1} \cdot \Delta R \alpha_{m v, t}-L_{m v, t-1} \cdot \Delta R \lambda_{m v, t} \\
& =A_{m v, t-1} \cdot \eta \cdot \Delta \widehat{F S M}_{t}-L_{m v, t-1} \cdot \gamma \cdot \Delta \widehat{S M}_{t} \\
& =A_{m v, t-1} \cdot \eta \cdot\left(\Delta \widehat{F S M}_{t}^{*}-\Delta \widehat{E}_{t}\right)-L_{m v, t-1} \cdot \gamma \cdot \Delta \widehat{S M}_{t} .
\end{aligned}
$$

The data used to quantify the valuation effects are given below:

\begin{tabular}{lll}
\hline Parameter Estimates & Initial Values (\$bil) \\
$\eta=0.74 \quad \gamma=0.87$ & $A_{m v}=3287 \quad L_{m v}=1709$ \\
\hline
\end{tabular}

The values of $\eta$ and $\gamma$ are from our model estimates and the positions are BEA's end-2004 values. With these parameters, the short-run response of the net position to alternative shocks is given below:

\begin{tabular}{lrlcc}
\hline Factor & \multicolumn{1}{c}{ Shock } & \multicolumn{3}{c}{ Valuation Effect on NDIP } \\
\cline { 3 - 5 } & & Mathematical & Dollar Value (\$bil) & Relative to Stock (\%) \\
U.S. Stock Market & $\Delta \widehat{S M}=0.01$ & $-L_{m v} \cdot \gamma \cdot \Delta \widehat{S M}$ & -24.3 & -1.4 \\
Foreign Stock Market & $\Delta \widehat{F S M}{ }^{*}=0.01$ & $A_{m v} \cdot \eta \cdot \Delta \widehat{F S M}$ & 23.4 & 0.7 \\
Exchange Rate & $\Delta \widehat{E}=0.01$ & $-A_{m v} \cdot \eta \cdot \Delta \widehat{E}$ & -23.4 & -0.7 \\
\hline
\end{tabular}

The estimates reveal that relatively small changes in asset prices translate into large valuation effects because the small changes in valuation rates are applied to large stocks of direct investment. And, as before, the results also reveal the potential for mutually offsetting effects. For example, if U.S. and foreign stock market prices increase simultaneously by one percentage point, then there is a decline in the net position of only $\$ 1$ billion, a relatively small magnitude.

\section{$5.2 \quad$ Long-run Effects}

The discussion so far has focused on quantifying the immediate effects and has ignored the fact that valuation effects impact the position further quarters out, even in the absence of further changes in inflation rates or other asset prices. Specifically, valuation effects today affect the corresponding stocks today which are 
then used to quantify valuation effects in the future. To quantify the longer-term impact we use dynamic simulations in which the history constitutes our baseline and focus on the following five shocks:

1. Exchange rate: Permanent 2.5 percent depreciation of the level of the dollar across all currencies,

2. Foreign stock market: Permanent 2.5 percent increase in the level of the stock-market prices in foreign currency across all currencies,

3. Foreign prices: Permanent 2.5 percent increase in the level of the foreign consumer price index,

4. U.S. stock market: Permanent 2.5 percent increase in the level of the U.S. stock-market price,

5. U.S. prices: Permanent 2.5 percent increase in the level of the U.S. nonresidential investment deflator.

All of these shocks begin in 2000q1 and the simulations are run through 2004q4.

\subsubsection{Exchange-Rate Shock}

A shock to the dollar affects the both the current cost and the market value position of U.S. direct investment abroad and, hence, the U.S. NDIP. The current-cost effect operates through the translation of the value of assets denominated in foreign currencies to dollars. The market-value effect operates through the change in the dollar value of the foreign stock market even though we assume the individual foreign stock market indexes remain unchanged. Specifically, the change in the dollar value of foreign stock price index is given by

$$
\widehat{F S M}_{t}=\widehat{F S M}_{t}^{*}-\Delta \widehat{E}_{t}
$$

Figure 17 illustrates the effect of the 2.5 percent depreciation on the valuation rate for DI abroad (top panel) and U.S. DI position abroad (bottom panel). The valuation rate at current cost increases by 1.3 percentage points in $2000 \mathrm{q} 1$ relative to its baseline, but is unchanged thereafter. Recall the valuation rate is a function of the change in the exchange rate, so the permanent depreciation affects the growth rate of the dollar in the first quarter of the shock only. The valuation rate for DI abroad at market value has a similar pattern. It increases by 1.9 percentage points relative to baseline at the onset of the shock. The different effects on current cost and market value are a result of the underlying models, which estimate a more sizeable effect from movements in the dollar value of the foreign stock market on the valuation rate than pure movement in the exchange rate as in the current cost. 


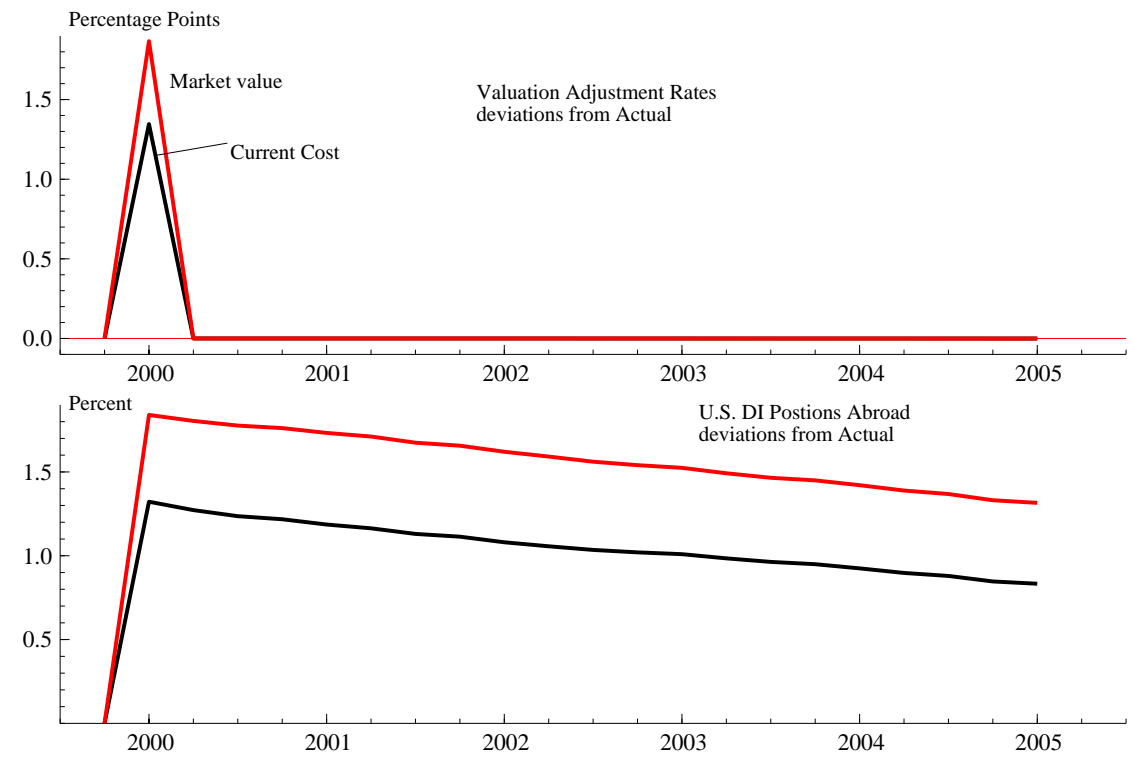

Figure 17 - Exchange-rate shock.

Assuming no change in DI outflows, the second panel shows the evolution of the stock of direct investment abroad. We find that at current-cost this stock increases by 1.3 percent at the onset of the shock; this is the short-run impact we reviewed in the previous sub-section. This initial increase is long lasting but its importance relative to baseline diminishes over time: after five years the boost from the dollar depreciation is about 70 percent of the original impact; of course, the deviation is still near 1 percent above baseline. For the market-value stock, the initial impact of the depreciation is to push the position up by 1.8 percent. This positive boost falls to about 1.3 percent by the end of 2005 .

Overall, a ceteris paribus dollar depreciation boosts the direct investment position abroad, which raises the net position. Although the effect of the depreciation is tempered over time, at five years out the DI position abroad is about 1 percent higher than baseline, depending on the valuation method.

\subsubsection{Foreign Stock-market Shock}

In this experiment we permanently increase the level of each individual foreign stock market index by 2.5 percent. This experiment solely affects the market value valuation adjustment and position for U.S. DI abroad. The effect of the higher foreign stock market on the valuation rate is shown in the top panel of Figure 18. The valuation rate moves up by nearly 2 percentage points in 2000q1 relative to its baseline. Assuming no change in DI outflows, the second panel shows the how the market-value of the DI position abroad evolves. We find that this position initially jumps up by 1.8 percent and this increase tapers down to 1.3 percent by the end of 2005. This experiment shows how the NDIP valued at current cost is boosted by foreign inflation. Of all the shocks we performed, this has the most modest effect on the net position. 


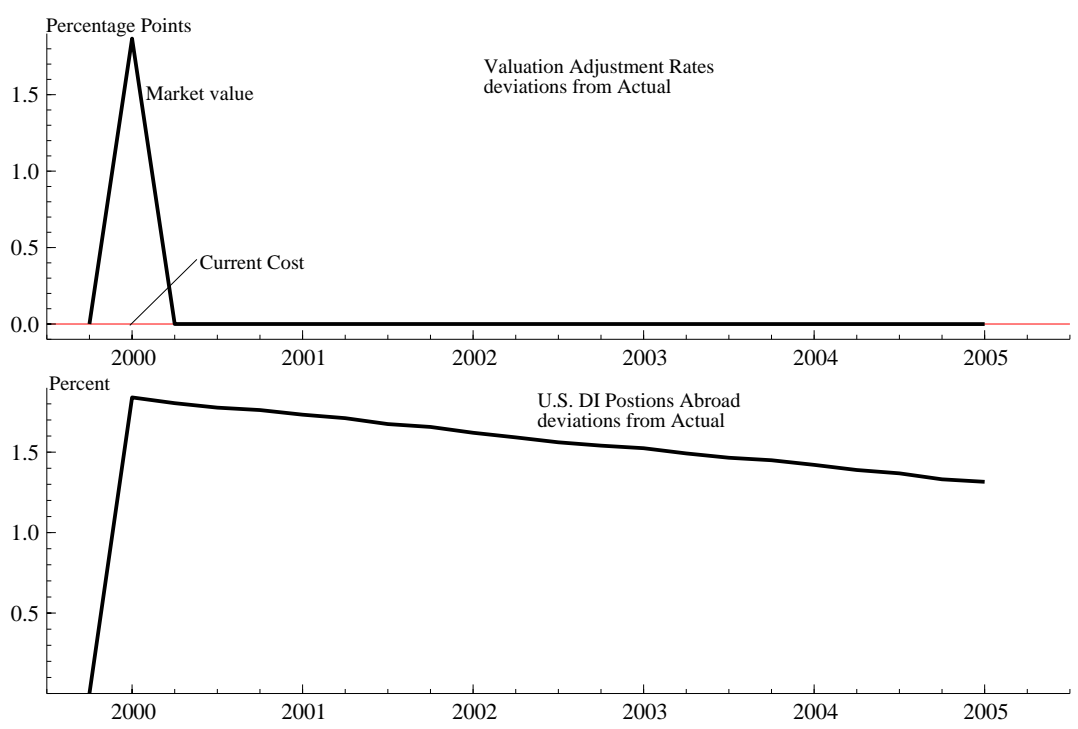

Figure 18 - Foreign stock-market shock.

\subsubsection{Foreign-price Shock}

In this experiment we raise the level of foreign prices by 2.5 percent. As shown in the top panel of figure 19 , this shock raises the valuation rate on DI abroad at current cost by 1.2 percentage points. There is no effect on the market value valuation rate because prices in this measure are equity prices, not prices on land, plants, equipment and inventories. As shown in the bottom panel, the DI position abroad at current cost is boosted by 1.2 percent in the first quarter, but tapers down to 0.8 percent five years out.

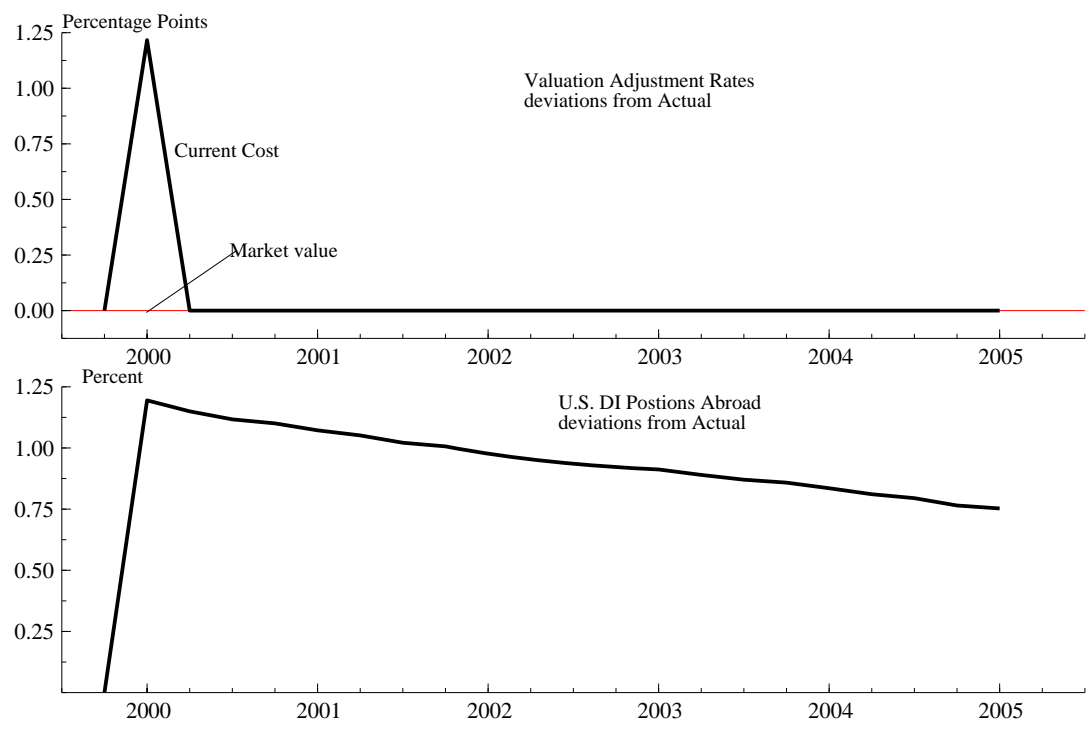

Figure 19 - Foreign-price shock. 


\subsubsection{U.S. Stock-market Shock}

In this experiment we permanently increase the level of the U.S. stock market index, the S\&P 500, by 2.5 percent. This experiment solely affects the market value valuation adjustment and DI position in the United States.

The effect of the higher U.S. stock market on the valuation rate is shown in the top panel of Figure 20. The valuation rate moves up by over 2 percentage points in 2000q1 relative to its baseline. Assuming no change in DI outflows, the bottom panel shows the impact on the market value DI position in the United States. We find the position at market value initially jumps up by over 2 percent. The positive boost tapers down to 1.6 percent by the end of 2004. So, a U.S. stock market boom raises the value of the direct-investment position in the United States and thus dampens the net direct-investment position. After four years the DI position in the United States is boosted by over $11 / 2$ percent.

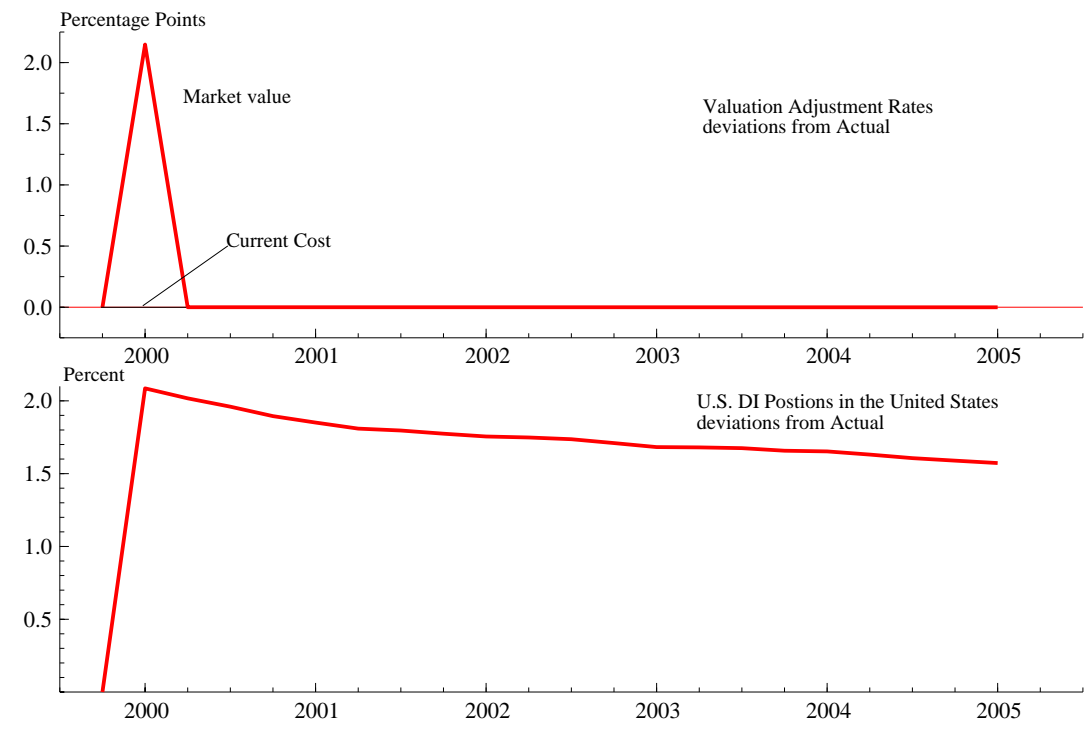

Figure 20 - U.S. stock-market shock.

\subsubsection{U.S. Investment Deflator Shock}

In this experiment we raise the level of the U.S. investment deflator by 2.5 percent. Our choice of deflator is motivated by BEA's current cost methodology which adjusts for prices of property, plant, equipment and inventories. With these considerations in mind, we shock the U.S. nonresidential business investment deflator. As shown in the first panel of figure 21, this boosts the valuation rate on DI in the United States at current cost by 2 percentage points. There is no effect on the market value valuation rate because prices in the market-valuation method are equity prices. As shown in the panel on the right, the U.S. DI position at current cost is boosted by nearly 2 percent in the first period, and the positive effect of the higher U.S. inflation tapers down to 1.1 percent five years out. So U.S. inflation dampens the net direct-investment position, with the DI stock in the United States over 1 percent higher four years after the shock. 


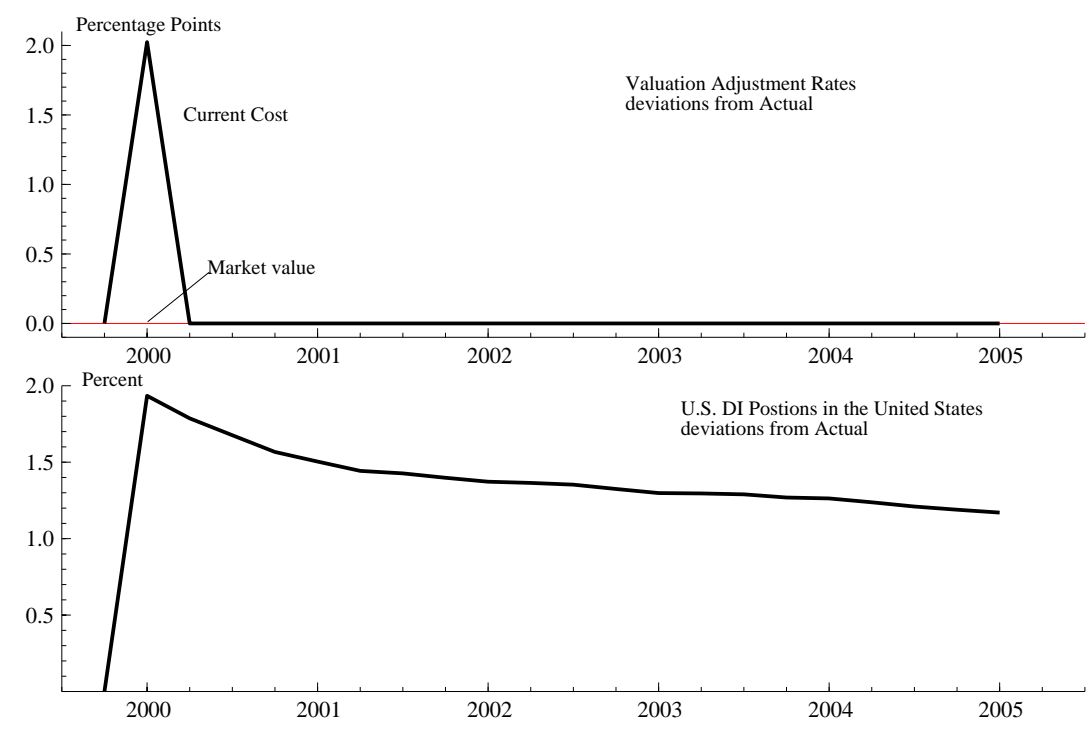

Figure 21- U.S. investment-deflator shock.

\section{Conclusion}

This paper takes an in-depth look at U.S. direct investment valuation adjustments. We develop a methodology to generate valuation adjustments at the quarterly frequency, which can be combined with the Bureau of Economic Analysis's quarterly direct investment flows to obtain quarterly estimates of direct investment assets and liabilities. Our methodology involves two steps. First, we estimate valuation adjustment models with annual data. Our models rely on variables that reflect terms used by the Bureau of Economic Analysis in their data construction: exchange-rate changes, changes in the price of products, and changes in stockmarket prices. Second, we apply quarterly data to the estimated models to generate quarter valuations and implement a procedure that ensures that the estimated valuations for the four quarters in a given year sum to the reported annual valuation adjustments.

With this framework we consider how asset price shocks affected the net direct investment position and, hence, net international investment position. We provide rules of thumb for how asset price shocks immediately affect the valuations and dynamic simulations to illustrate the longer-term effects on the valuation adjustments, DI positions and NDIP. Our estimates suggest that a one percent change in the exchange rate or prices leads to at least a $1 / 2$ percent change in the DI position. The largest impact on the DI position results from a change in the U.S. stock market; we find a one percent fall in the U.S. stock market translates into a $\$ 24$ billion drop in the value of DI in the United States (which is nearly $11 / 2$ percent of the value of the stock). 


\section{Appendix 1: Data Description}

Here we overview the construction of key independent variables used in the analysis.

DI-weighted exchange rate

$\frac{\Delta E_{t}}{E_{t-1}}$ is the DI-weighted exchange rate (foreign currency/dollar), end of period To construct this series we use data from 19 foreign countries, which represent the majority of the U.S. DI position abroad. The countries in our sample include Canada, France, Germany, Italy, Australia, Belgium, Spain, China, Hong Kong, Korea, Malaysia, Philippines, Singapore, Argentina, Brazil, Chile, Venezuela and Mexico. The weights vary by year, as the size of each country's year-end U.S. DIP varies relative to the total U.S. DIP Abroad in these countries.

DI-weighted foreign inflation

$\pi^{*}$ is the DI-weighted sum of foreign CPI inflation rates. We use the same methodology as with the DI-weighted exchange rate; we use the same 19 countries in the sample.

DI-weighted foreign stock market

In constructing FSM we use a DI-weighted stock market index, comparable to BEA's adjustment procedures. Specifically, emphasizing country coverage, we use individual stock market indexes for 20 countries, and the Morgan Stanley World, excluding the United States, for the remaining U.S. DI recipient countries. The individual countries we have in the sample include: Canada, France, Germany, Italy, the United Kingdom, Australia, Belgium, Spain, China, Hong Kong, Korea, Malaysia, the Philippians, Singapore, Argentina, Brazil, Chile, Venezuela, Russia and Mexico. These 20 countries represent 70 percent of 2003's U.S. DI Abroad at historic cost. Since the Morgan Stanley world, excluding the United States, index begins in mid-1996, our annual FSM only has observations beginning in 1997.

\section{Appendix 2: Iterative Procedure}

The process of obtaining quarterly valuation adjustments is iterative in nature. First, we use the estimated coefficients from the regressions using annual data to generate quarterly valuation rates. Second, we compute a first round of quarterly estimates of valuation adjustments. Third, with these quarterly estimates, we generate a first round of quarterly positions. These positions are said to be first round because they do not guarantee consistency with the annual figures. To ensure such consistency, we estimate a second round of quarterly positions where the valuation adjustment includes one-fourth of the difference between the annual valuation and the sum of the quarterly valuation estimates. This adjustment ensures that the sum of the second-round quarterly valuation adjustments equal the annual valuation adjustment. ${ }^{11}$ The iterative procedure is the same for assets, for liabilities, and for each type of valuation method. To describe the method we focus on assets and drop the subscript $i$.

\subsection{Step 1}

Use the estimate of $\theta_{i}$ to generate a first round of quarterly estimates of the valuation rates by applying the coefficient estimates to quarterly data:

$$
\widehat{R \alpha}_{t}^{q}=\widehat{\theta} \cdot X_{t}^{q}+\widehat{u}_{t}^{q}
$$

\footnotetext{
${ }^{11}$ One difference between BEA's valuation adjustment and our construct can arise because the summing of the quarterly changes in the exogenous variables is not the same as the annual change in these exogenous variables.
} 
where $X_{t}^{q}$ is the quarterly counterpart of $X_{t}^{a}$ (at a quarterly rate) and $\widehat{u}_{t}^{q}=\frac{\widehat{u}_{t}^{a}}{4}$; these residuals are not explained by key factors and thus we distribute its annual value evenly across the quarters in the year it is recorded. ${ }^{12}$

\section{$7.2 \quad$ Step 2}

Use first round quarterly valuation adjustments to estimate first round quarterly positions. For year $t_{1}$ the first quarter of the year is given by

$$
\begin{aligned}
\widehat{A}_{t_{1}}^{1} & =\widehat{A}_{t_{1}}^{0}+O_{t_{1}}^{1}+\widehat{\alpha}_{t_{1}}^{1} \\
& =\widehat{A}_{t_{1}}^{0}+O_{t_{1}}^{1}+\widehat{R \alpha}_{t_{1}}^{1} \cdot \widehat{A}_{t_{1}}^{0}
\end{aligned}
$$

where the initial condition, $\widehat{A}_{t_{1}}^{0}$, is the known annual position for the previous year. That is, $\widehat{A}_{t_{1}}^{0}=A_{t_{1}-1}^{a}$. The values for each quarter of year $t_{1}$ are

$$
\begin{aligned}
& \widehat{A}_{t_{1}}^{1}=\widehat{A}_{t_{1}}^{0}+O_{t_{1}}^{1}+\widehat{\alpha}_{t_{1}}^{1}=\widehat{A}_{t_{1}}^{0}+O_{t_{1}}^{1}+\widehat{R \alpha}_{t_{1}}^{1} \cdot \widehat{A}_{t_{1}}^{0} \\
& \widehat{A}_{t_{1}}^{2}=\widehat{A}_{t_{1}}^{1}+O_{t_{1}}^{2}+\widehat{\alpha}_{t_{1}}^{2}=\widehat{A}_{t_{1}}^{1}+O_{t_{1}}^{2}+\widehat{R \alpha}_{t_{1}}^{2} \cdot \widehat{A}_{t_{1}}^{1} \\
& \widehat{A}_{t_{1}}^{3}=\widehat{A}_{t_{1}}^{2}+O_{t_{1}}^{3}+\widehat{\alpha}_{t_{1}}^{3}=\widehat{A}_{t_{1}}^{2}+O_{t_{1}}^{3}+\widehat{R \alpha}_{t_{1}}^{3} \cdot \widehat{A}_{t_{1}}^{2} \\
& \widehat{A}_{t_{1}}^{4}=\widehat{A}_{t_{1}}^{3}+O_{t_{1}}^{4}+\widehat{\alpha}_{t_{1}}^{4}=\widehat{A}_{t_{1}}^{3}+O_{t_{1}}^{4}+\widehat{R \alpha}_{t_{1}}^{4} \cdot \widehat{A}_{t_{1}}^{3} .
\end{aligned}
$$

\subsection{Step 3}

The above estimates of the valuation adjustments and positions are computationally feasible because all the required data are available before hand. However, one cannot guarantee that the fourth-quarter position estimate from this first round will be consistent with the known annual position estimate. In other words, full consistency between the annual and quarterly estimates of the position requires a procedure such that $\widehat{A}_{t_{1}}^{4}=A_{t_{1}}^{a}$, where $A_{t_{1}}^{a}$ is the BEA reported annual position in year $t_{1}$. The first round fails to ensure consistency for quarterly and annual positions because it cannot guarantee that the sum of the quarterly estimates of the valuation adjustments will be equal to the known annual value. In other words, there is no assurance that $\alpha_{t}^{a}=\Sigma_{q} \widehat{\alpha}_{t}^{q}$, where data for $\alpha_{t_{1}}^{a}$ are those reported from the BEA.

Thus we construct an iteration error for quarter $q$ of year $t_{1}$ as

$$
e_{t_{1}}^{q}=\frac{\alpha_{t_{1}}^{a}-\Sigma \widehat{\alpha}_{t_{1}}^{q}}{4}
$$

which allows computing a second-round of valuation adjustment as

$$
\widehat{\widehat{\alpha}}_{t_{1}}^{q}=\widehat{\alpha}_{t_{1}}^{q}+e_{t_{1}}^{q}=\widehat{R \alpha}_{t_{1}}^{q} \cdot \widehat{A}_{t_{1}}^{q-1}+e_{t_{1}}^{q} .
$$

\footnotetext{
${ }^{12}$ For the $\mathrm{S} \& \mathrm{P}$ we use the monthly average for the 3 rd month of each quarter.
} 
These second round valuation adjustments allow us to compute a second round of quarterly positions as

$$
\begin{aligned}
& \widehat{\widehat{A}}_{t_{1}}^{1}=\widehat{\widehat{A}}_{t_{1}}^{0}+O_{t_{1}}^{1}+\widehat{\widehat{\alpha}}_{t_{1}}^{1} \\
& \widehat{\widehat{A}}_{t_{1}}^{2}=\widehat{\widehat{A}}_{t_{1}}^{1}+O_{t_{1}}^{2}+\widehat{\widehat{\alpha}}_{t_{1}}^{2} \\
& \widehat{\widehat{A}}_{t_{1}}^{3}=\widehat{\widehat{A}}_{t_{1}}^{2}+O_{t_{1}}^{3}+\widehat{\widehat{\alpha}}_{t_{1}}^{3} \\
& \widehat{\widehat{A}}_{t_{1}}^{4}=\widehat{\widehat{A}}_{t_{1}}^{3}+O_{t_{1}}^{4}+\widehat{\widehat{\alpha}}_{t_{1}}^{4},
\end{aligned}
$$

where $\widehat{\widehat{A}}_{t_{1}}^{0}=\widehat{A}_{t_{1}}^{0}=A_{t_{1}-1}^{a}$. By design, this second round of quarterly positions satisfies the terminal condition $\widehat{A}_{t_{1}}^{4}=A_{t_{1}}^{a}$. Specifically,

$$
\begin{aligned}
\widehat{\widehat{A}}_{t_{1}}^{4} & =A_{t_{1}-1}^{a}+\Sigma_{q} O_{t_{1}}^{q}+\Sigma_{q} \widehat{\widehat{\alpha}}_{t_{1}}^{q} \\
& =A_{t_{1}-1}^{a}+\Sigma_{q} O_{t_{1}}^{q}+\Sigma_{q} \widehat{\alpha}_{t_{1}}^{q}+\Sigma_{q} e_{t_{1}}^{q} \\
& =A_{t_{1}-1}^{a}+\Sigma_{q} O_{t_{1}}^{q}+\Sigma_{q} \widehat{\alpha}_{t_{1}}^{q}+\Sigma_{q}\left(\frac{\alpha_{t_{1}}^{a}-\Sigma_{q} \widehat{\alpha}_{t_{1}}^{q}}{4}\right) \\
& =A_{t_{1}-1}^{a}+\Sigma_{q} O_{t_{1}}^{q}+\Sigma_{q} \widehat{\alpha}_{t_{1}}^{q}+\alpha_{t_{1}}^{a}-\Sigma_{q} \widehat{\alpha}_{t_{1}}^{q} \\
& =A_{t_{1}-1}^{a}+\Sigma_{q} O_{t_{1}}^{q}+\alpha_{t_{1}}^{a} \\
& =A_{t_{1}-1}^{a}+O_{t_{1}}^{a}+\alpha_{t_{1}}^{a} \\
& =A_{t_{1}}^{a} .
\end{aligned}
$$

This procedure holds for all years. 


\section{References}

[1] Bergsten, C.F., and J. Williamson, 2004, "Overview: Designing a Dollar Policy," in Dollar Adjustment: How Far? Against What?, Institute for International Economics, Washington D.C.

[2] Cline, W., 2005, United States as a Debtor Nation, Institute for International Economics, Washington D.C.

[3] Landfeld, J.S., and A.M. Lawson, 1991, "Valuation of the U.S. Net International Investment Position," Survey of Current Business, May, p40-49.

[4] Lane, P. and G. Milesi-Ferretti, 2005, "A Global Perspective on External Positions," IMF Working Paper $\mathrm{WP} / 05 / 161$.

[5] Gourinchas, P. and H. Rey, 2005a, "International Financial Adjustment," NBER Working Paper No. 11155.

[6] Gourinchas, P. and H. Rey, 2005b, "From World Banker to World Venture Capitalist: US External Adjustment and the Exorbitant Privilege," NBER Working Paper No. 11563.

[7] Hendry, D. F. and J. Doornik, 1999, Empirical Econometric Modelling Using PcGive, London: Timberlake.

[8] Higgins, M., Klitgaard, T. and C. Tille, 2005, "The Income Implications of Rising U.S. International Liabilities," Federal Reserve Bank of New York Current Issues in Economics and Finance, 11(12). 